\title{
HEAT TRANSFER IN SALT CAVERNS
}

\author{
Pierre Bérest \\ LMS, Ecole Polytechnique, CNRS UMR 7649, 91128 Palaiseau, France \\ berest@Ims.polytechnique.fr
}

\begin{abstract}
Several aspects of the thermodynamic behavior of salt caverns containing brine, oil, natural gas, air or hydrogen are discussed. It is shown that natural convection always appears in a liquid-filled cavern. This is not true in the case of gas caverns. Gas type, brine temperature at the cavern bottom and water vapor content are influential. Equations are obtained for the thermodynamic behavior of the fluids stored in a cavern during injection-withdrawal. Thermal evolution of a liquid-filled cavern at rest is slow; rapid injection and withdrawal are adiabatic and lead to small temperature changes. Heat capacity is much smaller in a gas cavern, temperature evolutions are much faster, and heat transfer from the rock mass must be taken into account. Evolutions can be described through a relatively simple equation. A simple model describing pressure and temperature in the wellbore during gas withdrawal is obtained.
\end{abstract}

Key words: Salt caverns; Gas storage caverns; CAES; Thermodynamics of salt caverns; Water vapor in a salt cavern

\section{Highlights}

- Conditions leading to natural convection in a cavern

- Inversion of temperature gradient in a gas cavern

- Equations for evolution of stored fluid temperature during injection-withdrawal

- Adiabatic and non-adiabatic behavior of a liquid-storage cavern 
- Thermodynamic behavior of a gas-storage cavern

- A closed-form solution for gas flow in a wellbore

\section{Introduction}

Salt caverns are deep cavities that are created by solution mining in both bedded and domal salt formations. They are connected to the ground level through a cased and cemented well. Strings are set in the well to allow injection or withdrawal of fluids into or from the cavern. These caverns range in volume from $V_{c}=5000 \mathrm{~m}^{3}$ to $5,000,000 \mathrm{~m}^{3}$ and in depth from $H=200 \mathrm{~m}$ to $H=2000 \mathrm{~m}$. When solution mining is completed, the cavern can be filled with crude oil, LPG, natural gas, hydrogen, compressed air, etc. During operation, fluids are injected or withdrawn from the cavern, and heat is exchanged with the rock mass, leading to pressure and temperature changes in the cavern. An abundant literature - mentioned in the course of the paper - was dedicated to various aspects of these thermodynamic effects in specific sites. The objective of this paper is to describe some of these effects and to prove that their main features can be captured by relatively simple models.

\section{Natural convection in a salt cavern}

In this section, the theoretical conditions leading to the onset of natural convection in a cavern are discussed.

\subsection{Fluid pressure in a cavern}

In a gas-storage cavern, gas pressure $(P)$ at casing-shoe depth $(H)$ varies between a maximum and a minimum pressure, typically $P_{\min }=\gamma_{\min } H, \quad P_{\max }=\gamma_{\max } H$, where $\gamma_{\text {min }}=0.6 \times 10^{-2} \mathrm{MPa} / \mathrm{m}$, and $\gamma_{\max }=1.8 \times 10^{-2} \mathrm{MPa} / \mathrm{m}$ are the minimum and maximum "gradients". Maximum gas pressure is smaller than geostatic pressure, $P_{\infty}=\gamma_{R} H$, $\gamma_{R}=2.2 \times 10^{-2} \mathrm{MPa} / \mathrm{m}$. where $\gamma_{R}$ is the average volumetric weight of the rock formation. In natural gas caverns, gas used to be injected in summer and withdrawn in winter; at a $H=$ 1300-m depth, for instance, pressure varied from $8 \mathrm{MPa}$ to $22 \mathrm{MPa}$, typically. Prompted by the needs of energy traders, cycles tend to be more frequent. In compressed air storage, 
pressure is cycled every day between $5 \mathrm{MPa}$ and $7 \mathrm{MPa}$, typically. A gas-storage cavern contains gas and brine (hence, water vapor) as, during the initial gas fill (debrining) some brine, trapped into the sump at the cavern bottom, cannot be removed from the cavern. This brine, which is cold (see Section 4.2), plays a significant role in cavern thermodynamics. In liquefied or liquid (or supercritical) products storage, a central tube is left in the wellbore, and brine is injected in the central tube when hydrocarbon is withdrawn from the annulus between the cemented casing and the central tube (and vice versa): most often, cavern pressure is halmostatic, or $P_{h}=\gamma_{b} H, \gamma_{b}=1.2 \times 10^{-2} \mathrm{MPa} / \mathrm{m}$ is brine volumetric weight. However, cavern pressure is higher than halmostatic during tightness tests and lower during workovers. In the following, cavern pressure $\left(P_{c}\right)$ is the fluid pressure computed at casingshoe depth.

\subsection{Temperature in a cavern}

\subsubsection{Brine-filled cavern}

Figure 1 displays the temperature profile along a vertical axis in the cavern and access well of a brine cavern at Etrez, France, operated by Storengy ( ${ }^{1}$ Brouard, 1998). For this cavern, $V_{c}$ $=8000 \mathrm{~m}^{3}$, and the cavern's top and bottom depths are $920 \mathrm{~m}$ and $960 \mathrm{~m}$, respectively. On the left hand-side, a slope discontinuity can be observed at a 700-m depth. Its origin is in the contrast between the thermal conductivities of salt and marls. Heat flux through conduction is continuous through any discontinuity, $q=K_{R} d T_{R} / d z=K_{\operatorname{marl}} d T_{\text {marl }} / d z$. For rock salt, $K_{R}=6 \mathrm{~W} / \mathrm{m} /{ }^{\circ} \mathrm{C}$; for marls, $K_{\text {marl }}=3 \mathrm{~W} / \mathrm{m} /{ }^{\circ} \mathrm{C}$. The thermal gradient $d T / d z$ is divided by 2 at the interface between salt and marls. Another slope discontinuity, originating in convection, can be observed at shallow depth (a few dozen meters below ground level). The test is performed in February. At night, the wellhead is cold. Cold brine flows down in the wellbore to be replaced by warmer brine from below which, in turn, cools when in contact with the wellhead. The natural geothermal gradient is $G_{R}^{\infty}=d T_{R}^{\infty} / d z=1.6 \times 10^{-2 \circ} \mathrm{C} / \mathrm{m}$ in the salt formation. The thermal conductivity of the brine is $K_{b}=0.6 \mathrm{~W} / \mathrm{m} /{ }^{\circ} \mathrm{C}$ : if heat transfer in the cavern brine were through conduction, one would expect that the temperature gradient be larger in the brine mass than in the rock mass. In fact, the temperature gradient in the cavern is as small as $G_{c}=3.4 \times 10^{-3}{ }^{\circ} \mathrm{C} / \mathrm{m}$, clear evidence of the effects of natural convection. At the cavern bottom, the brine is warmer (hence, lighter) than it is at the cavern top. Due to 
buoyancy effects, brine rises; it cools along its upward path to the cavern top and ultimately returns to the cavern bottom, leading to the creation of convection cells. Brine is stirred by convection, and its temperature homogenizes. Numerical computations ( ${ }^{2}$ Karimi-Jafari 2007) using Boussinesq' linearization of the equations describing natural convection in the cavern were performed. Axisymmetry is assumed. The ADINA CFD modulus was used ( $k-\varepsilon$ model, no slip at cavern walls, velocity profile at cavern wall according to the Reichard law). On Figure 2, steady state flow is reached (after $1.110^{8} \mathrm{~s}$, or 12 days). Iso-values of the stream function $\psi=\psi(r, \theta), \quad v_{r}=-\partial \psi / \partial \theta, \quad v_{\theta}=\partial \psi / \partial r$ are represented on Figure 2, left: three convection cells develop, the lower cell rolls counter-clockwise. On Figure 2, right, velocity magnitude is represented; it is largest along the axis of symmetry where it is faster than 0.2 $\mathrm{mm} / \mathrm{s}(17 \mathrm{~m} /$ day).

Figure 3 displays the case of a brine-filled cavern at Stassfurt, Germany. The cavern volume is $V_{c}=13000 \mathrm{~m}^{3}$, and the cavern's top and bottom are $440 \mathrm{~m}$ and $650 \mathrm{~m}$, respectively. As in the previous example, the thermal gradient in the cavern is much smaller than the natural geothermal gradient, which is $G_{R}^{\infty}=1.8 \times 10^{-2 \circ} \mathrm{C} / \mathrm{m}$ in the salt formation - clear evidence of the onset of convection.

\subsubsection{Gas-filled cavern}

In a gas cavern, convection also can be observed. In fact, onset of convection is certain in a brine cavern (see Section 1.3). This is less true in a gas cavern and, in many cases, only the upper part of the cavern is the seat of perennial natural convection, as explained below.

Figure 4 represents the temperature profile in the S107 natural gas cavern at Stassfurt, Germany. ${ }^{4}$ Klafki et al. (2003) mention that the top and bottom of the cavern are $968 \mathrm{~m}$ and 1070 m, respectively. However, Fig. 4 suggests that actual depths might be slightly larger. Cavern volume is $V_{c}=288000 \mathrm{~m}^{3}$; it can be divided in three parts, whose radii are, from top to bottom, $20 \mathrm{~m}, 60-65 \mathrm{~m}$ and $46 \mathrm{~m}$. The cavern had been kept at rest for 2.5 months before the temperature log was run. Thermal convection is active in the upper part of the cavern: the thermal gradient there is much smaller than the geothermal gradient in the rock mass $\left(G_{R}^{\infty}=1.35 \times 10^{-2 \circ} \mathrm{C} / \mathrm{m}\right)$. In the lower part of the cavern, the gradient sign changes (gradient inversion) slightly above the cavern bottom. The lower part of the logging tool was below the 
brine-gas interface when the temperature at the lowest point on Fig. 4 was measured, which means that this point is representative of the temperature at the interface depth. Gradient inversion will be discussed in Section 4.

\subsection{First condition for onset of natural convection}

Gas thermal constants are given in Table 1 (at $\theta=25^{\circ} \mathrm{C}$ and $P_{N}=0.10325 \mathrm{MPa}$ ). Heat capacity, $C_{P}$, is an increasing function of pressure. At $20 \mathrm{MPa}$ and $30{ }^{\circ} \mathrm{C}$, it is $3400 \mathrm{~J} / \mathrm{kg} /{ }^{\circ} \mathrm{C}$ for $\mathrm{CH} 4$ and $1600 \mathrm{~J} / \mathrm{kg} /{ }^{\circ} \mathrm{C}$ for air ( ${ }^{6}$ Schlichtenmayer et al. 2015). In this paper, we are mainly interested in a semi-quantitative description of the phenomena observed in actual caverns rather than in accurate numerical computations. For this reason, dependency of the thermal parameters upon temperature is not taken into account. Note, however, that it can play a role. For instance, it is known that, for a given geometry, rotation of convection cells is in opposite directions when a gas and a liquid is considered, as the sign of $d \mu / d T$ ( $\mu$ is the fluid viscosity) is not the same.

Mechanical equilibrium in a fluid requires that temperature be a function of depth only. At equilibrium, $\operatorname{gra} d P=\rho(P, T) \vec{g}$; hence, $\operatorname{cu} \overrightarrow{u r l}(\rho \vec{g})=\left(\frac{\partial \rho}{\partial T}\right) \vec{g} \wedge \operatorname{gra} d T=\overrightarrow{0}$ and $T=T(z)$. Such an equilibrium is stable when the temperature gradient is oriented upward $(G=d T / d z<0)$. A downward-oriented temperature gradient $(G=d T / d z>0) 0)$ is not a sufficient condition for onset of natural convection (i.e., instability). Even in an infinite fluid medium (No viscous boundary layer at cavern wall or viscous dissipation in the fluid body is considered.), this gradient must be larger than a certain threshold, the adiabatic gradient, which can be defined as follows. When a fluid particle rises by $d z<0$, its pressure immediately decreases by $d P=\rho g d z$ to reach mechanical equilibrium with the surrounding fluid. Because of this expansion, liquid temperature drops. As a consequence, heat transfer from the surrounding fluid takes place to reach thermal equilibrium. However, this process is much slower than the mechanical process; in fact, when particle rise is fast, insufficient time is given for heat transfer, and particle expansion is adiabatic. In the case of a non-viscous ideal gas, an adiabatic expansion can be described as $T d s=C_{P} d T_{a d}-d P / \rho=0$, where $s$ is the gas entropy per unit of mass, $C_{P}$ is the gas thermal capacity (when gas pressure is kept 
constant), $\rho=P / r T$ is its density, from which $d T_{a d}=g d z / C_{P}$. This temperature change must be compared to the geothermal temperature change, or $d T_{c}=G_{R}^{\infty} d z$. When $G_{a d}=g / C_{P}<G_{R}^{\infty}$, the rising particle is warmer (and lighter) than its environment and keeps rising: convection appears. Gravity acceleration is $g=10 \mathrm{~m} / \mathrm{s}^{2}$; heat capacity is $C_{P}=3400 \mathrm{~J} / \mathrm{kg} /{ }^{\circ} \mathrm{C}$ for natural gas (at $30^{\circ} \mathrm{C}$ and $20 \mathrm{MPa}$ ), $C_{P}=1100 \mathrm{~J} / \mathrm{kg} /{ }^{\circ} \mathrm{C}$ for air $\left(\right.$ at $30^{\circ} \mathrm{C}$ and $7 \mathrm{MPa}$ ), and $C_{P}=14000 \mathrm{~J} / \mathrm{kg} /{ }^{\circ} \mathrm{C}$ for hydrogen. In other words, as $G_{R}^{\infty}=1.6-1.8 \times 10^{-2}{ }^{\circ} \mathrm{C} / \mathrm{m}$ in a salt formation, onset of convection is likely in an air-storage facility $\left(g / C_{P}=9 \times 10^{-3}{ }^{\circ} \mathrm{C} / \mathrm{m}\right)$, highly likely in a natural gas storage $\left(\mathrm{g} / C_{P}=3 \times 10^{-3}{ }^{\circ} \mathrm{C} / \mathrm{m}\right)$ and certain in a hydrogen storage $\left.\left(g / C_{P}=0.7 \times 10^{-3}{ }^{\circ} \mathrm{C} / \mathrm{m}\right)\right)$.In the case of a liquid, $d T_{a d}=\alpha T d P / \rho C_{P} ; \alpha=-\partial \rho(T, P) / \partial T$ is the thermal expansion coefficient (for a gas, $\alpha T=1$.) For brine, $\alpha_{b}=4.4 \times 10^{-4} /{ }^{\circ} \mathrm{C} ; \quad T=300 \mathrm{~K}$ is typical, $C_{P}^{b}=3800 \mathrm{~J} / \mathrm{kg} /{ }^{\circ} \mathrm{C}$, and $G_{a d}=3.5 \times 10^{-4 \circ} \mathrm{C} / \mathrm{m}$ is much smaller than the geothermal gradient: onset of convection is certain in a brine-filled cavern, as suggested by the examples shown on Figs. 1 and 3. However, these simple arguments fail to take into account several factors, which will be discussed below.

\subsection{Induced geothermal gradient}

In the previous section, it was assumed that the geothermal gradient is the same in the cavern $\left(G_{c}^{\infty}\right)$ as in the rock mass $\left(G_{R}^{\infty}\right)$. In fact, because gas (or liquid) conductivity is less than rock conductivity, the geothermal gradient at rest (when no convection takes place) is larger in the cavern fluid than in the rock mass. The adiabatic gradient $\left(G_{a d}\right)$ must be compared to $G_{c}^{\infty}$ rather than $G_{R}^{\infty}$. Let $T_{R}$ and $T_{F}$ be the temperature distributions at rest in the rock mass and in the cavern fluid, respectively. Both are harmonic functions, $\Delta T_{R}=0$ and $\Delta T_{F}=0$. Consider, for instance, the case of a spherical cavern, radius $a$, whose origin is at the center of the cavern whose depth is $H$; spherical coordinates are used, and $z=H+r \cos \theta$ is oriented downward. Rock temperature and fluid temperature are $T_{R}(r, \theta)=T_{\infty}(H)+G_{R}^{\infty} r \cos \theta+A a^{3} \cos \theta / r^{2}$ and $T_{F}=T_{\infty}(H)+G_{c}^{\infty} r \cos \theta$, respectively; $A$ and $G_{c}^{\infty}$ are two constants. At the cavern wall, temperatures and heat flux are continuous, $T_{R}=T_{F}$ and $K_{F} \partial T_{F} / \partial n=K_{R} \partial T_{R} / \partial n$, from which it is inferred that the geothermal gradient at rest in the cavern is $G_{c}^{\infty} / G_{R}^{\infty}=3 K_{R} /\left(2 K_{R}+K_{F}\right)$. In most cases, $K_{F}$ is much smaller than $K_{R}$ (for rock 
salt, $K_{R}=6 \mathrm{~W} / \mathrm{m} /{ }^{\circ} \mathrm{C}$; for brine, $K_{F}=0.6 \mathrm{~W} / \mathrm{m} /{ }^{\circ} \mathrm{C}$; for air or for hydrogen, $K_{F}=0.026 \mathrm{~W} / \mathrm{m} /{ }^{\circ} \mathrm{C}$ or $0.185 \mathrm{~W} / \mathrm{m} /{ }^{\circ} \mathrm{C}$ respectively - see Table 1 ) and the "induced" geothermal gradient in the fluid at rest is larger than the geothermal gradient in the rock mass (for air, $G_{c}^{\infty}=1.5 G_{R}^{\infty}$ ), making onset of convection somewhat easier than predicted in Section 1.3.The induced geothermal gradient also depends on cavern age. During the leaching period, which is several years long, cold water pumped from a lake or a shallow aquifer is injected in the cavern. When leaching is completed, the cavern brine is colder than the rock mass by a couple of dozen of ${ }^{\circ} \mathrm{C}$. After debrining, the cavern walls are cold ( ${ }^{7}$ Walden et al., 2001), and the same can be said of the brine left at the cavern bottom. Warming brine and rock mass is slow ( ${ }^{8}$ Fosse and Røvang, 1998), as discussed later. The transient induced geothermal gradient is difficult to compute.

\subsection{Wet gas and dry gas}

In many cases (Section 2), cavern gas is saturated with water vapor. (Equilibrium with sump brine must be reached.) In principle, when computing adiabatic gas expansion, the effect of condensation must be taken into account, and the wet adiabatic gradient is smaller than the dry adiabatic gradient ('Sivoukhine, 1982, p. 499-501). Let $m_{g}, m_{v}, m_{L}$ be the mass of gas, water vapor and liquid water, respectively. When condensation starts, $m_{L}=0$ and $\dot{m}_{L}+\dot{m}_{v}=0$. The vapor pressure at saturation, $P_{v}^{s}(T)$, is a function of temperature only. During adiabatic evolution, the entropy of the mixture, $s=\sum_{i} m_{i} s_{i}, i=v, L, g$, is constant, and

$$
\left(s_{v}-s_{L}\right) d m_{v}+\frac{m_{v}}{T}\left(C_{P}^{v} d T_{a d}-\frac{d P_{v}^{s}}{\rho_{v}}\right)+\frac{m_{v}}{T}\left(C_{P}^{g} d T_{a d}-\frac{d P_{g}}{\rho_{g}}\right)=0
$$

Let $L=\left(s_{v}-s_{L}\right) T$ be the latent heat capacity for the liquid-vapor transition; taking into account $d P_{v}^{s} / d \boldsymbol{T}=L \rho_{v} / T$ (Clapeyron's law), $d P_{g}=\rho_{g} g d z$ (mechanical equilibrium), and $P_{i}=\rho_{i} r_{i} T$ for $i=v, g$ (state equations) 


$$
\left.\frac{d T}{d z}\right|_{\text {wet }}=\frac{g}{C_{P}^{g}\left(1+\frac{r_{g} P_{v}^{s}}{r_{v} P_{g}}\left[L\left(\frac{L}{r_{V} T^{2}}-\frac{2}{T}\right)+C_{P}^{v}\right] / C_{P}^{g}\right)}
$$

The difference between the wet adiabatic gradient $G_{a d}^{\text {wet }}$ and the dry adiabatic gradient $G_{a d}^{d r y}$ (which equals $g / C_{P}^{v}$ ) is proportional to the $P_{v}^{s} / P_{g}$ ratio. This ratio between vapor pressure and gas pressure is not very small in the atmosphere $\left(P_{g}=P_{\text {air }}=0.1 \mathrm{MPa}\right.$; at $\theta=30^{\circ} \mathrm{C}, P_{v}^{s}\left(30^{\circ} \mathrm{C}\right)=4.25 \mathrm{kPa}$ and $P_{v}^{s} / P_{\text {air }}=4 \%$, see Section 2$)$ and the difference is significant when meteorological phenomena are concerned. The same is not true for a gas cavern, in which $P_{g}=10 \mathrm{MPa}$, and, when $\theta=50^{\circ} \mathrm{C}, P_{v}^{s}\left(50^{\circ} \mathrm{C}\right)=9 \mathrm{kPa}$ are typical.

\subsection{Second condition for onset of natural convection}

The condition for onset of natural convection, $G_{a d}<G_{c}^{\infty}$, is a necessary condition. In the analysis, viscous effects were not taken into account. In fact, in a cavity of (very) small dimensions, viscosity can impede natural convection. The set of equations describing natural convection in a cavern (conservations of mass, energy and momentum) must be solved numerically. However, steady-state convective flow can be described through linearized equations (Boussinesq approximation) ( ${ }^{10}$ Landau and Lifschitz, 1971). This set of equations highlights the significance of three dimensionless constants, Prandtl, Grashof and Nusselt numbers: $\operatorname{Pr}=v / k$, where $v=$ kinematic viscosity, $k=$ gas thermal diffusivity; $G r=g \alpha G a^{4} / v^{2}$, where $a=$ cavern characteristic length, $\alpha=$ the thermal expansion coefficient of the fluid, and $G=G_{c}-G_{a d}$, where $G_{c}$ is the actual thermal gradient in the cavern; and $\mathrm{Nu}=\bar{H} a / K_{F}$ where $\bar{H}$ is the heat-transfer coefficient at the cavern wall (defined in Section 5.1). Natural convection starts when $G$ is larger than the value given by a certain combination of $\mathrm{Gr}$, $\mathrm{Pr}$ and $\mathrm{Nu}$ that depends on cavern shape and boundary conditions. For an elongated cylindrical cavern, convection appears when the Rayleigh number $\mathrm{Ra}=\mathrm{Pr} \cdot \mathrm{Gr}$ is larger than a value that depends on $\mathrm{Nu}$ and is smaller than $10^{3}\left({ }^{10}\right.$ Landau and Lifschitz, 1971). The Prandtl number can be written $\operatorname{Pr}=\mu C_{P} / K$; for most gases (Table 1), dynamic viscosity is in the range $\mu=1-2 \times 10^{-5}$ Pa.s $\quad C_{P}=1-2 \times 10^{3} \mathrm{~J} / \mathrm{kg} / \mathrm{K}, \quad$ and $\quad K=2 \times 10^{-5}$ Pa.s. Also, $g=10 \mathrm{~m} / \mathrm{s}^{2}, G=1.5 \times 10^{-2}{ }^{\circ} \mathrm{C} / \mathrm{m}, \alpha_{g}=3 \times 10^{-3} /{ }^{\circ} \mathrm{C}$ and, for standard caverns, $a=10-50 \mathrm{~m}$. 
The Rayleigh number ( $=$ Pr.Gr $)$ is larger than $10^{10}$, a figure for which natural convection is turbulent. In other words, a cavern contains so large a fluid body that the condition relative to the adiabatic gradient is a sufficient condition for onset of convection. For instance, ${ }^{4} \mathrm{Klafki}$ et al., 2003 computed natural convection in the cavern represented on Fig. 4. A stable vortex (The horizontal component of gas speed was high.) was observed in the lower part of the cavern, an independent convection cell (upstream at the wall, downstream in the center) was observed in the main cavern, and flow was unsteady in the narrow upper part. Maximal velocities were smaller than $0.5 \mathrm{~m} / \mathrm{s}$. This computation highlights the importance of cavern shape on the pattern of convection cells pattern (see also Fig. 2).

\section{Water vapor in the cavern}

Moisture content is a critical issue when operating a gas cavern. It was proven in Section 1.5 that its influence on the onset of natural convection is minor. However, when gas containing water vapor is withdrawn from a cavern, gas pressure and temperature drop in the wellbore, leading to the possible formation of hydrates in the upper part of the wellbore (a severe operational problem, discussed in Section 6). In fact, natural gas injected in a cavern is relatively dry. In France, for instance, water vapor concentration (or $c_{v}=m / V_{N}=P_{v} P_{N} / r_{v} T_{N} P_{g}$, where the subscript $N$ is for normal conditions, $P_{N}=0.10325 \mathrm{MPa}$, and $T_{N}=273 \mathrm{~K}$.) must be less than $c_{v}=46 \mathrm{mg} / \mathrm{Nm}^{3}$ ( ${ }^{11}$ Louvet et al., 2018). However, there is a thin brine layer at the cavern wall $\left(70 \mathrm{~cm}^{3} / \mathrm{m}^{2}\right.$, see ${ }^{12} \mathrm{Kökritz}$ and Walden, 1994) and a (much larger) amount of brine in the sump at the cavern bottom mentioned in Section 1.1. Equilibrium requires, at least in principle, that brine is saturated with dissolved natural gas and that cavern gas is saturated with water vapor. The partial pressure of water vapor at saturation, or $P_{v}^{s}$, is a function of temperature (for instance, Rankine's formula predicts: $P_{v}^{s}[T]=f P_{a t m} \exp (13.7-5120 / T)$, with $T$ in $\mathrm{K}$; for pure water, $f=1$, and for saturated brine, $f=$ 0.75 , according to Raoult's law).

Following gas injection or withdrawal, temperature changes in the cavern, and gas is either over- or under-saturated with water vapor in the new temperature conditions. Water vaporizes or condenses until, after some time, equilibrium is reached again. Consider an airstorage cavern of volume $V_{c}=400000 \mathrm{~m}^{3}$ : air is withdrawn rapidly from the cavern, whose 
pressure drops from $7 \mathrm{MPa}$ to $5 \mathrm{MPa}$ : air temperature drops from $\theta=50^{\circ} \mathrm{C}$ to $\theta=30^{\circ} \mathrm{C}$ (see Section 5.12), and saturated vapor pressure drops from $P_{v}^{s}\left(50^{\circ} \mathrm{C}\right)=9 \mathrm{kPa} P_{v}^{s}\left(30^{\circ} \mathrm{C}\right)=3.15 \mathrm{kPa}$. The mass of water vapor in air or $m_{v}=P_{v}^{s} V_{c} / r_{v} T_{c}$, where $r_{v}=460 \mathrm{~J} / \mathrm{kg} /{ }^{\circ} \mathrm{C}$, drops from 24,000 $\mathrm{kg}$ to $9,000 \mathrm{~kg}$. Water vapor concentration also drops, from $1050 \mathrm{mg} / \mathrm{Nm}^{3}$ to $515 \mathrm{mg} / \mathrm{Nm}^{3}$. When withdrawal starts, gas becomes oversaturated with water vapor, and it hazes - or even rains - in the cavern. Latent heat generated by condensation of $\delta m=15,000 \mathrm{~kg}$ of water ( $L \delta m=3.7510^{10}$ Joules) is provided to the gas mass, and the gas temperature drop is slightly smaller than predicted from gas-expansion equations $\left(\begin{array}{rlll} & { }^{\circ} \mathrm{C}\end{array}\right)$, by $\delta \theta=L \delta m / \rho_{g} C_{P}^{g} V_{c}=1{ }^{\circ} \mathrm{C}$, approximately $\left(\rho_{g} C_{P}^{g}=0.8 \times 10^{5} \mathrm{~J} / \mathrm{m}^{3} /{ }^{\circ} \mathrm{C}\right)$. At the end of the withdrawal phase, air warms to return to thermal equilibrium with the rock mass $\left(\theta=50^{\circ} \mathrm{C}\right)$. Later on, warm gas is injected in the cavern, pressure and temperature increase. Vaporization then takes place at the vicinity of the interface; latent heat now is provided by brine and gas close to the brine/gas interface (rather than by the whole gas mass) - see Fig. $5\left({ }^{13}\right.$ Thaule and Gentsch, 1994). Note the temperature gradient inversion at a depth of 1280 $\mathrm{m}$, discussed below. This resaturation process seems to be relatively slow. ${ }^{12}$ Köckritz and Walden (1994) and ${ }^{14}$ Köckritz et al. (1996) studied vaporization rate at the brine-gas interface at the laboratory scale and proposed the following law: $\dot{m}_{v}=A \bar{\beta}\left(P_{s}-P_{v}(t)\right) / r_{v} T$, where $m_{v}=P_{v} V_{c} / r_{v} T$, i.e., $\dot{m}_{v}=A \bar{\beta}\left(m_{s}-m_{v}(t)\right) / V_{c} ; A$ is the brine-gas interface area; and $\bar{\beta}$ is a constant. Vapor mass is the time constant for the vaporization process, $t_{c}=V_{c} / A \bar{\beta}$. The ratio between cavern volume $\left(V_{c}\right)$ and interface area $(A)$ in an elongated cylindrical cavern typically is $V_{c} / A=200 \mathrm{~m} .{ }^{14} \mathrm{Köckritz}$ et al. (1996) measured $\bar{\beta}=5 \times 10^{-5} \mathrm{~m} / \mathrm{s}$ (at the lab); they suggest that this figure must be increased by a factor of 20 when convection is active, leading to $t_{c}=130$ days (no convection) and $t_{c}=6.5$ days (convection is active). Warm gas injection at the cavern top and slow re-saturation may explain why withdrawn gas often is under-saturated with vapor, see Section 4.2.In other words, a pressure cycle is not a symmetric process: it provides condensation heat to the entire gas body and withdraws vaporization heat from the vicinity of the brine/gas interface (In the example above, vaporization heat is $L \delta m=3.75 \times 10^{10} \mathrm{~J}$, an amount which is able to cool a $10,000 \mathrm{~m}^{3}$ volume of brine by $\left.1^{\circ} \mathrm{C}\right)$.

\section{Examples of temperature evolution during gas injection-withdrawal}


In this section, examples of temperature profile evolution when gas pressure varies significantly are presented and the role of vapor content discussed.

\subsection{S107 Cavern, Stassfurt, Germany}

Cavern S107 was described briefly in Section 1.2.2 and Fig. 4. During a 14-day period, three gas withdrawals $\left(60,000 \mathrm{Nm}^{3} / \mathrm{hr}\right.$ over 20 hours, $100,000 \mathrm{Nm}^{3} / \mathrm{h}$ over 12 hours, 142,000 $\mathrm{Nm}^{3} / \mathrm{hr}$ over 7 hours, followed by a 77 -hour standstill) and a $61,000-\mathrm{Nm}^{3} / \mathrm{hr}$ injection over 61 hours were managed (for natural gas, $1 \mathrm{Nm}^{3}=0.68 \mathrm{~kg}$ ). Temperature profiles were measured through a Raman optical fiber (Fig. 6); they remain almost vertical during withdrawal, evidence of the perennial effect of thermal convection in the main cavern body. The height of the cool zone in the lower part of the cavern (below the gradient inversion depth) increases. A separate convection cell is present in the upper (and thinner) part of the cavern, where gas cooling is slower. Gas temperature immediately above the gas/brine interface (noted by the sinker bar being in the brine, ${ }^{4}$ Klafki et al., 2003) cools significantly, and it is reasonable to assume that brine below the interface cools accordingly.

\subsection{Huntorf caverns}

Figure $7\left({ }^{15}\right.$ Quast, 1983) displays temperature profiles in the NK1 cavern of the Huntorf compressed-air storage facility not long after the first air fill. (The shape of the Huntorf caverns is represented on Fig. 14). At the cavern bottom, the sump brine is still quite cold. In Fig. 7, air flowrates (in $\mathrm{kg} / \mathrm{s}$ ) are positive when gas is withdrawn. Each of the four profiles corresponds to a given instant of an injection-withdrawal sequence (1. standstill; 2 . end of withdrawal; 3. end of a standstill and 4. end of an injection phase). The temperature vertical gradient is inverse (Its sign is opposite to the geothermal gradient - i.e., no convection takes place), and its value is $G_{c}=d T / d z=-10 \times 10^{-30} \mathrm{C} / \mathrm{m}$ ( $z$ oriented downward). According to ${ }^{15}$ Quast (1983), this inverse gradient can be explained by brine temperature at the cavern bottom, which is much colder than the rock-mass temperature. This gradient remains constant even when the average gas temperature changes significantly. This explanation is reasonable; however, it must be noted that, in addition, onset of convection is more difficult 
in the case of air (or oxygen). More recent profiles would have shed some light on this, but, unfortunately, they are not available.

\subsection{Enterprise cavern}

Figure 8 (16Skaug et al., 2010) displays temperature profiles before and after a natural gas withdrawal in a salt cavern operated in Texas by Enterprise. Measurements were performed in April and May 2009, before and after movement of gas. (Of the initial inventory, 22\% was withdrawn, and the initial cavern pressure at casing shoe depth was $P=1.85 \times 10^{-2} H, P_{c}$ in $\mathrm{MPa}, H$ in $\mathrm{m}$.) When the cavern was leached out is unknown; however, it is known that a sonar survey had been run in 2002, 7 years before the 2009 test. The cavern volume is $V_{c}=$ $430000 \mathrm{~m}^{3}$ (2.6 10 bbls), and its depth is between $H=3600 \mathrm{ft}(1100 \mathrm{~m})$ and $3960 \mathrm{ft}(1200$ m). Here, again, thermal convection is impeded in the lower part of the cavern; at rest, gradient inversion depth is $3720 \mathrm{ft}$. Figure 8 suggests that temperature also was measured below the brine-gas interface. More than 7 years after debrining was completed, brine temperature is significantly colder $\left(32^{\circ} \mathrm{C}\right)$ than that of the cavern gas - and colder still after gas withdrawal $\left(27^{\circ} \mathrm{C}\right)$. It is likely that, in absence of brine, the gas temperature should have dropped by a larger amount in the lower part of the cavern. Brine convection takes place below the brine-gas interface, effectively cooling at least the upper part of the brine body. However, brine temperature remains warmer than gas temperature in the lower part of the cavern, and thermal convection also is triggered in the gas, leading to an almost vertical temperature profile in the lower part of the cavern. This tentative explanation (Few data are available.) is discussed in more detail in Section 4.

\section{Inversion of temperature gradient and tentative synthesis}

\subsection{Temperature distribution at the cavern bottom}

It was noted in the above examples (Figs. 4 to 6 and Fig. 8) that the temperature gradient, which was oriented upward in the main cavern body, experiences an inversion in the lower part of the cavern. This seems to be a general property of gas-storage caverns: “... frequently, measurements in caverns reveal a drop in temperature a few meters above the brine level. This is attributable to the consumption of heat energy for evaporation" ${ }^{17}$ Berger et al., 2002, p.56); "The brine remaining in the bottom of the cavern is usually cooler than 
the stored gas" (18Istvan, 1996, p. 3); and "Above the gas-brine level the temperature decreases significantly which is a typical effect observed in caverns" ( ${ }^{19}$ Schneider et al., 2002, p. 263). Temperature profiles reproduced by ${ }^{20}$ Karimi-Jafari et al. (2014), ${ }^{21}$ Krieter and Gotthardt (2015), ${ }^{22}$ Osnes et al. 2007 or ${ }^{17}$ Berger et al., 2002 (see Fig. 9) display the same pattern: along the cavern's axis of symmetry, the thermal gradient is positive and low in the upper part of the cavern $\left(d T / d z=6 \times 10^{-30} \mathrm{C} / \mathrm{m}\right)$; it is negative and high above the sump at the cavern bottom $\left(d T / d z=-0.15^{\circ} \mathrm{C} / \mathrm{m}\right)$. The ratio between cold-zone height and cavern height $\left(h^{-} / h\right)$ is defined on Fig. 9; it varies from 10\% (on Figs. 4 and 5) to 60\% (Kiel 102 cavern, discussed by ${ }^{19}$ Schneider et al., 2007) and $100 \%$ (at Huntorf, see Fig. 7). It was said that, after the first gas injection ("debrining"), some brine $\left(1000-10,000 \mathrm{~m}^{3}\right)$ is left at cavern bottom in the sump formed by the insoluble fractions that fell during solution mining. This brine is cold and remains cold for a while. It seems reasonable to infer that the lower part of the cavern gas is the seat of thermal conduction and water vapor diffusion (two slow transfer processes) and that the upper part is the seat of natural convection, leading to much faster vapor transfer. Temperature gradient (and heat flux) seem to be discontinuous at the interface between these two parts of the cavern; in fact, heat is transferred by conduction from a thin interface to both the lower and upper zones and by conduction + convection in the upper zone. Let $S_{0}$ be the surface on which convection vanishes, $\vec{u}=\overrightarrow{0}$, where $\vec{u}$ is the gas speed, and $S_{1}$ is a surface slightly above $S_{0}$. When density changes are

neglected, $\int_{S 1} \vec{u} \cdot \vec{n}_{1} d A_{1}=0$. The energy equation is written $d\left(\rho C_{P}^{g} T\right) / d t=\operatorname{div}\left(-K_{g} \overrightarrow{\operatorname{grad} T}\right)$; when steady state is considered, heat is withdrawn from the gas slice between $S_{0}$ and $S_{1}$ through upward and downward conduction, $\int_{S_{0}}-K_{g} \partial T / \partial n_{0} d A_{0}+\int_{S_{1}}-K_{g} \partial T / \partial n_{1} d A_{1}$, and brought into the gas slice through convection, $\int_{S_{1}} \rho_{g} C_{P}^{g} T\left(\vec{u} \cdot \vec{n}_{1}\right) d A_{1}$.

\subsection{A tentative synthesis}

Main findings of Sections 1 to 4.1 can be summarized as follows. The theoretical conditions for onset of natural convection in a cavern are met: the Rayleigh number, Ra = Pr.Gr, is so large that convection, when it exists, is turbulent; the adiabatic gradient is significantly smaller than the geothermal gradient (Although this is less true for air storage.); and in a gas cavern, the wet adiabatic gradient almost equals the dry gradient. Convection stirs gas 
cavern, whose temperature and moisture content should be homogeneous.In fact, in actual caverns, the general picture is more complex. Natural convection is always present in a liquid-filled cavern. In a gas-filled cavern, the cavern can be subdivided in two parts: (1) the upper part is the seat of natural convection, the temperature gradient is oriented upward, heat and moisture transfer is fast; and (2) in the lower part, the temperature gradient is oriented downward, no convection takes place, and heat transfer is slow. The gradient inversion depth varies widely from one cavern to another. One exception is the Huntorf storage cavern, where, at least early on, the temperature gradient was oriented downward in the entire cavern. In addition, it is observed that natural gas is not always vapor-saturated, especially at the cavern top ( ${ }^{14}$ Köckritz et al.,1994, ${ }^{15}$ Quast 1983), which can be related to the absence of convection immediately above the brine-gas interface where, to a certain extent, water vapor is trapped by the downward-oriented temperature gradient. These features can be related to the thermal history of a cavern and the presence of a cold sump at the cavern bottom. During the leaching phase, the rock mass is cooled significantly by circulation of cold water; several years after leaching is completed, the temperature at the cavern wall is significantly different from the geothermal temperature ('Walden et al., 2001). This is also true when brine at the cavern bottom, trapped in the insoluble sump, is considered: it is colder than the rock mass and conditions for onset of convection are not met in the lower part of the cavern. In addition, observations suggest that sump brine might remain colder than the rock mass during the entire cavern life because of several mechanisms. Heat is transferred from sump brine through the cavern walls and the brinegas interface by conduction, a slow process - especially when gas is concerned. Gas is injected at the cavern top; it is warmer $\left(60^{\circ} \mathrm{C}\right)$ than cavern gas and under-saturated with water vapor; it may remain stagnant at the cavern top. Conversely, ${ }^{23}$ Reitze and von Tryller (2005) suggest that, during gas withdrawal, a cold column forms at the center of the cavern that is colder than the gas that is closer to the cavern walls; after some time, this column drops to the cavern bottom. Both contribute to less effective convection. In Section 1.3, another reason was suggested. During a pressure cycle, brine at the bottom of the cavern is cooled during each cycle by two mechanisms: possible natural convection in the sump brine following a severe gas pressure drop (Enterprise cavern, Section 3.3); and, probably more frequent, vaporization following an increase in gas temperature during the warming phase of the cycle - two effects that have no counterpart during the cooling phase of the cycle. 
This might explain why brine, which is cooler than the rock mass when cavern leaching is completed, remains consistently cold, at least when the cavern is submitted to frequent and severe pressure and temperature cycles. These explanations are tentative. Published temperature profiles are scarce and, in many cases, relevant information (cavern age, cavern pressure history before temperature is recorded) is missing.

\section{Thermodynamic behavior of the stored fluid during injection-withdrawal}

\subsection{General equations}

In this section, it is accepted that, when analyzing the overall thermodynamic behavior of a cavern, it is sufficient to consider the cavern's average temperature $\left(T_{c}\right)$ and pressure $\left(P_{c}\right)$. The set of equations satisfied by the rock mass and the stored fluid can be written

$$
\begin{gathered}
\frac{\partial T_{R}}{\partial t}=k_{R} \Delta T_{R} \\
G_{R}^{\infty}(z)=d T_{R}^{\infty}(z) / d z \quad T_{R}(t=0)=T_{R}^{\infty}(z) \\
T_{R}=T_{c} \quad \text { at cavern wall } \\
v_{c}=v_{c}\left(P_{c}, T_{c}\right) \quad h_{c}=h_{c}\left(P_{c}, T_{c}\right) \\
m\left(\dot{h}_{c}-v_{c} \dot{P}_{c}\right)=Q+<\dot{m}>\left(h_{i n j}-h_{c}\right)-L \dot{m}_{v} \\
d\left(\rho_{f} V\right) / d t=\dot{m} \\
\dot{V}_{c} / V_{c}=\beta_{c} \dot{P}-\alpha_{R} \Phi[T(\underline{x})]+\dot{\varepsilon}^{c r}
\end{gathered}
$$

Equations $(3,4,5)$ describe heat transfer through the rock mass: Equation $(3)$ is the heatconduction equation in the rock mass ( $k_{R}$ is the thermal diffusivity of salt) ; Eq. (4) contains the boundary and initial thermal conditions, respectively (Other initial conditions also can be considered); and Eq. (5) is the boundary condition at the cavern wall. In fact, many authors (e.g., ${ }^{24}$ Kushnir et al., 2012)., assume that fluid temperature at the cavern wall is not equal to the rock temperature, and some surface heat-transfer coefficient $(\bar{H})$ must be taken into account, $\bar{H}\left(T_{R}-T_{c}\right)=K_{R} \partial T_{R} / \partial n$. Selecting the value of this parameter $(\bar{H})$ is difficult. (There 
is a lack of field data, and this value depends strongly on roughness of the cavern wall and convection intensity.) In fact, the turbulent boundary layer at the cavern wall is likely to be thin, making $\bar{H}$ quite small; in this paper, it is assumed that temperature is continuous at cavern wall. The stored fluid can be characterized [see Eq. (6)] by its state equation - i.e., the specific volume, $v_{c}=1 / \rho_{c}$, of the stored fluid as a function of $P_{c}$ and $T_{c}, v_{c}=v_{c}\left(P_{c}, T_{c}\right)$, and by a thermodynamic potential - for instance, its enthalpy per unit of mass, $h_{c}=h_{c}\left(P_{c}, T_{c}\right)$. The energy balance equation is shown in Eq. (7), where $Q=\int_{\Sigma} K_{R} \partial T_{R} / \partial n d \Sigma$ is the heat flux transferred from the rock mass to the gas through the cavern wall, and $m$ is the mass of fluid in the cavern. Kinetic energy is disregarded: when gas is withdrawn/injected from/to the cavern, the gas rate in the wellbore, which has a cross-sectional area smaller than 0.1 $\mathrm{m}^{2}$, typically is $u=10 \mathrm{~m} / \mathrm{s}$, (less in the case of a liquid). Rates are much smaller when considering the cavern's bulk volume, whose cross-sectional area typically is several thousands of $\mathrm{m}^{2}$. The system is open, and mass is exchanged with the wellbore through the cavern chimney; $\langle\dot{m}\rangle=\dot{m}$ when $\dot{m}>0$ and $\langle\dot{m}\rangle=0$ when $\dot{m}<0$. At the cavern entrance, fluid pressure is continuous. When gas is injected, temperature is not continuous, and a jump in enthalpy must be considered, $h_{i n j}-h_{c}=C_{P}\left(T_{i n j}-T_{c}\right)$, where $T_{i n j}$ is the temperature of the injected fluid. No such term exists when fluid is withdrawn $(\dot{m}<0)$. In a gas cavern, gas often is compressed before being injected; however, in most cases, $T_{\text {inj }}$ is smaller than $60{ }^{\circ} \mathrm{C}$ to prevent excessive thermal expansion of the wellhead and steel casings. The latent heat associated with condensation/vaporization is $\operatorname{Lim}_{v}$; it will not be considered in the following. Equation (8) is the mass-conservation equation for the stored fluid, $V$ is the fluid volume; Eq. (9) describes cavern volume evolution, where $V_{c}$ is the cavern volume, $V=V_{c}$, when there is only one fluid in the cavern. The elastic compressibility of the cavern is $\beta_{c}$, which depends on the elastic properties of the rock mass $(\bar{E}$ and $\bar{v})$ and cavern shape - not on cavern size. For an idealized spherical or cylindrical cavern, $\beta_{c}=3(1+\bar{v}) / 2 \bar{E}$ and $\beta_{c}=2\left(1-v^{2}\right) / \bar{E}$, respectively; $\beta_{c}=1.4 \times 10^{-4} / \mathrm{MPa}$ is typical, larger values are found in flat caverns $\left({ }^{25} \mathrm{Bérest}\right.$ et al., 1999); $\dot{\varepsilon}^{c r}$ is the cavern creep-closure rate, which depends on cavern pressure history, cavern depth and shape, and the creep properties of salt. Generally speaking, $\dot{\varepsilon}^{c r}<0$, except after a swift pressure increase (26Bérest et al., 2015), and $\dot{\varepsilon}^{c r}$ varies from $\dot{\mathcal{\varepsilon}}^{c r}=-10^{-5} / \mathrm{yr}$ at a $250-\mathrm{m}$ depth to $\dot{\varepsilon}^{c r}=-$ several \%/yr at a 2000-m depth. Term $\alpha_{R} \Phi[T(x)]$ is 
the thermal expansion of the cavern when the rock mass is warmed or cooled. It is zero in the case of an idealized spherical or cylindrical cavern and, in general, is exceedingly small (27Karimi-Jafari et al. 2007); it is disregarded in the following, $\Phi=0$, and $\alpha_{R}=4 \times 10^{-5} /{ }^{\circ} \mathrm{C}$ is the thermal expansion coefficient of rock salt. One may ask whether cavern volume, or $V c$, which experiences large changes in the long term, must be updated. In the following, focus is put on two problems: effects of a fast gas pressure drop (Sections 5.5 to 5.12), during which cavern additional shrinkage is small; and long-term evolution (centuries) of a brine-filled abandoned cavern, for which extremely accurate predictions are out of reach. For this reason, cavern volume is not updated; it could be; an interesting attempt can be found in ${ }^{28}$ Kalhedi et al.

\subsection{Temperature evolution in a liquid-filled cavern}

In the case of a liquid, $\dot{v}_{L}=v_{L}^{0}\left(\alpha_{L} \dot{T}_{c}-\beta_{L} \dot{P}_{c}\right)$ and $\dot{h}_{L}=C_{P}^{L} \dot{T}_{c}-\beta_{L} v_{L}^{0} P \dot{P}$; Eqs. $(7,8,9)$ can be rewritten:

$$
\begin{gathered}
m\left(C_{P}^{L} \dot{T}_{c}-\alpha_{L} T_{c} v_{L}^{0} \dot{P}\right)=Q+<\dot{m}>C_{P}^{L}\left(T^{i n j}-T_{c}\right) \\
\dot{m} / m=-\alpha_{L} \dot{T}_{c}+\beta \dot{P}_{c}+\dot{\mathcal{\varepsilon}}^{c r}
\end{gathered}
$$

where, in principle, $\beta=\beta_{c}+\beta_{b} ; \beta$ is the cavern compressibility factor. When the cavern is filled with brine, $\beta=4-5 \times 10^{-4} / \mathrm{MPa}$ is typical $\left({ }^{25}\right.$ Bérest et al., 1999). Note, however, that when the fluid is saturated with brine, mass exchange takes place between the rock mass and the cavern brine. Concentration at saturation is an increasing function of temperature and pressure. For instance, according to Le Chatelier-Braun principle, when pressure increases, dissolution occurs, and the volume of formed brine is smaller than the sum of the initial volume of brine and the volume of dissolved salt. This effect is taken into account by increasing the value of the coefficient $\beta_{b}$ slightly (see ${ }^{25}$ Bérest et al., 1999). This simplification holds when long-term evolutions are considered - in other words, when enough time is left to reach saturation.

\subsection{Temperature evolution in an open liquid-filled cavern}


In an open brine-filled cavern, when long-term evolutions are considered, $\dot{P}=0$ and $\dot{m}<0$. (In most cases, brine is expelled from the cavern; see, for instance, ${ }^{29}$ Brouard et al., 2013). Thus, Eq. (10) can be rewritten:

$$
\rho_{L} V_{c} C_{P}^{L} \dot{T}=\int_{\Sigma} K_{R} \frac{\partial T_{R}}{\partial n} d \Sigma
$$

an equation which, together with Eqs. $(3,4,5)$, allows computation of cavern temperature

evolution. Let $a$ be a characteristic length of the cavern. Taking into account $K_{R}=\rho_{R} C_{P}^{R} k_{R}$, two characteristic times can be built, $a^{2} / k_{R}$ and $a^{2} / k_{R} \chi$, where $\chi=\rho_{R} C_{P}^{R} / \rho_{L} C_{P}^{L}$ is the ratio between the volumetric heat capacities of rock and fluid. In the case of a liquid (brine or oil), these two quantities are of the same order of magnitude (for brine, $\chi=0.55$ ), and any of them can be considered to discuss orders of magnitude. Figure 10 displays brine temperature evolution after leaching is completed in a cavern with volume $V_{c}=8,000 \mathrm{~m}^{3}$ cavern, and an average depth $H=950 \mathrm{~m}$. A typical characteristic length is $a=V_{c}^{1 / 3} / 2$, and the characteristic time is $V_{c}^{2 / 3} / 4 k_{R}=1$ year, a period after which $75 \%$ of the initial temperature gap vanishes (Fig. 10). Even in such a small brine-filled cavern, brine warming is a slow process. In a larger cavern (for instance, one with a volume of $V_{c}=512,000 \mathrm{~m}^{3}$ ), the characteristic time is 40 years, and brine warming is very slow. A more general discussion, including the effects of cavern shape, can be found in ${ }^{27}$ Karimi-Jafari et al., 2007.

\subsection{Pressure and temperature evolutions in a liquid-filled cavern}

With the cavern closed at ground level, $\dot{m}=0$ and $-\alpha_{L} \dot{T}_{c}+\beta_{L} \dot{P}_{c}+\dot{\varepsilon}^{c r}=0$; Eq. (10) is written

$$
\left(C_{P}^{L}-\frac{\alpha_{L}^{2} T_{c}}{\beta \rho_{L}}\right) \dot{T}_{c}+\frac{\alpha_{L} T_{c}}{\beta \rho_{L}} \dot{\mathcal{\varepsilon}}^{c r}=\frac{1}{m} \int_{\Sigma} K_{R} \frac{\partial T_{R}}{\partial n} d \Sigma
$$

where $\rho_{L}=1 / v_{0}, C_{P}^{L}-\alpha_{L}^{2} T / \beta \rho_{L}=C_{v}^{L^{\prime}}$ is not very different from $C_{v}^{L}=C_{P}^{L}-\alpha_{L}^{2} T / \beta_{L} \rho_{L}$. For brine, $\quad \beta=4 \times 10^{-4} / \mathrm{MPa}, \quad \alpha_{b}=4.4 \times 10^{-4} /{ }^{\circ} \mathrm{C}, \quad T=300 \mathrm{~K}, \quad \rho_{b}=1200 \mathrm{~kg} / \mathrm{m}^{3}, \quad$ and $\alpha_{L}^{2} T / \beta \rho_{L}=120 \mathrm{~J} / \mathrm{kg} /{ }^{\circ} \mathrm{C}$ is significantly smaller than $C_{P}^{b}=3600 \mathrm{~J} / \mathrm{kg} / \mathrm{K}$. (Generally speaking, theoretical considerations lead to distinguishing between such notions as $C_{P}^{L}, \mathrm{C}_{V}^{L}$, etc. It must be recognized, that, from a practical perspective, the difference is small in the case of a liquid.) In a $H=1000-\mathrm{m}$ deep cavern, when cavern pressure is halmostatic $\left(P_{c}=\rho_{b} g H\right)$, 
$\dot{\mathcal{E}}^{c r}=-3 \times 10^{-4} / \mathrm{yr}$ is typical ( ${ }^{1}$ Brouard, 1998), and the effect of creep must be taken into account when $\dot{T}$ is not much larger than $-\alpha_{L} T_{c} \dot{\varepsilon}^{c r} / \beta \rho_{L} C_{P}^{L}=0.05^{\circ} \mathrm{C} / \mathrm{yr}$. Now, when cavern temperature (rather than cavern pressure) is eliminated between Eqs. (10) and (11),

$$
\beta^{\prime} \dot{P}_{c}=-\dot{\varepsilon}^{c r}+\frac{\alpha_{L} \chi}{V_{c}} \int_{\Sigma} k_{R} \frac{\partial T_{R}}{\partial n} d \Sigma
$$

( $\beta^{\prime}$ is slightly distinct from $\beta$ ). This equation proves that in a shut-in cavern, in which, initially, the stored fluid is colder than the rock mass, cavern pressure increases due to two distinct phenomena: cavern creep closure, and brine expansion. The relative significance of these two phenomena depends on many factors, among which are cavern depth and cavern age ( ${ }^{26}$ Karimi-Jafari et al., 2007). Cavern size plays no role in creep closure; however, the brine expansion rate is inversely proportional to the square of characteristic cavern length (a). The following example was made available by Storengy $\left({ }^{30}\right.$ Van Sambeek et al., 2005). Three caverns $(A, B, C)$ were being leached in the same salt formation at comparable depth (Casing-shoe depths were 1450 m, 1465 m and 1590 m, respectively - Fig. 11). Hence, the cavern creep-closure rate $\left(\dot{\varepsilon}^{c r}\right)$ is almost the same in the three caverns. The three caverns were shut in, and the wellhead-pressure evolution was measured. Pressure increase rates were: $\dot{P}=4 \mathrm{MPa} / \mathrm{yr}$ in Cavern A $\left(V_{c}=346,000 \mathrm{~m}^{3}\right), 5.9 \mathrm{MPa} / \mathrm{yr}$ in Cavern B $\left(V_{c}=147,000 \mathrm{~m}^{3}\right)$ and $10 \mathrm{MPa} / \mathrm{yr}$ in Cavern $\mathrm{C}\left(V_{c}=48,600 \mathrm{~m}^{3}\right)$ - i.e., inversely proportional to $V_{c}^{2 / 3}$, which proves that brine thermal expansion was the main factor leading to pressure increase. As will be seen in Section 5, temperature increase is much faster in a gas-filled cavern.

These effects are important in an abandoned cavern. When thermal equilibrium is reached before abandonment, cavern pressure $\left(P_{c}\right)$ increases due to creep; however, the creep rate decreases, as it is a non-linear function of the difference $P_{\infty}-P_{c}$ between geostatic pressure and cavern pressure. Ultimately, in principle, cavern pressure reaches geostatic pressure, and cavern creep closure extinguishes itself. In fact, ultimate pressure often is smaller than geostatic pressure because salt permeability, even if exceedingly small, allows some pressure relief. When thermal equilibrium is not reached before abandonment, thermal expansion leads to additional pressure increase, and geostatic pressure can be exceeded, with a risk of hydro-fracking. Abundant literature has been dedicated to this issue $\mathrm{e}^{3,31,32,33}$. 


\subsection{Fast injection or withdrawal in a liquid-filled cavern}

In this paragraph, liquid is rapidly (less than one day) injected/withdrawn in/from a liquidfilled cavern. During such a short period, liquid evolution can be considered as adiabatic, $Q=$ 0 (from Section 5.3); in addition, creep closure can be disregarded, $\dot{\varepsilon}^{c r}=0$. The case of an oil-filled cavern is discussed here. From Eqs. (10) and (11):

$$
\dot{m} / m=-\alpha_{O} \dot{T}_{c}+\beta_{O} \dot{P}_{c} \quad C_{P}^{O} \dot{T}_{c}-\alpha_{O} v_{0}^{o} T_{c} \dot{\boldsymbol{P}}_{c}=\frac{<\dot{m}>}{m} C_{P}^{O}\left(T^{i n j}-T_{c}\right)
$$

The injection case $(\dot{m}>0)$ and the withdrawal case $(\dot{m}<0)$ are slightly different. In the withdrawal case $(\dot{m}<0)$, a simple formula is obtained:

$$
\left.\frac{d T_{c}}{d P_{c}}\right|_{a d}=\frac{\alpha_{O} T_{c}}{\rho_{O} C_{P}^{O}}
$$

In other words, a pressure drop generates a (small) temperature drop. This is illustrated clearly by tests performed in the $J$ cavern of the Manosque site (in France) operated by Geostock ( ${ }^{33}$ Gatelier et al., 2008) from June 21, 2005 to February 8, 2006. The cavern contained oil (and a small amount of brine at the cavern bottom) and had a volume of $V_{c}=$ $314000 \mathrm{~m}^{3}$ and an oil density of $\rho_{0}=800-840 \mathrm{~kg} / \mathrm{m}^{3}$. Temperature was measured at a 780$\mathrm{m}$ depth, where oil pressure was 6.2 MPa.

Injections followed by withdrawals generated significant pressure changes (Fig. 12, left). Temperatures changed accordingly (Fig. 12, right). The ratio between measured temperature and pressure changes is $\dot{T}_{c} / \dot{P}_{c}=0.16^{\circ} \mathrm{C} / \mathrm{MPa}$. Values $\alpha_{o}=9 \pm 1 \times 10^{-4} /{ }^{\circ} \mathrm{C} ; T_{c}=304 \mathrm{~K}$ and $\rho_{O} C_{P}^{O}=1.8 \pm 0.2 \times 10^{6} \mathrm{~J} / \mathrm{m}^{3}{ }^{\circ} \mathrm{C}$ lead to a predicted value of $\alpha_{O} T / \rho_{O} C_{P}^{O} \square 0.15^{\circ} \mathrm{C} / \mathrm{MPa}$, which is in good agreement with the measured value. Note that in a brine-filled cavern, the ratio $\alpha_{b} T / \rho_{b} C_{P}^{b}=0.03^{\circ} \mathrm{C} / \mathrm{MPa}$ is five times smaller than in an oil-filled cavern, and temperature changes are more difficult to measure. However, they allow the resolution of temperature gages to be checked ( ${ }^{27}$ Brouard et al., 2013).

\subsection{Gas caverns}


For an ideal gas, $P v=r_{g} T$ and $\dot{h}=C_{P} \dot{T}$. (The value of $r_{g}=R / M_{g}$ epends on the gas considered.) In the following, we consider only swift (lasting a few days) gas injections/withdrawals. Creep closure can be neglected, $\dot{\varepsilon}^{c r}=0$; generally, gases are much more compressible than liquids, and cavern volume changes are neglected, $\dot{m} v+m \dot{v}=0$. In a liquid-filled cavern, over a short period of time, heat flow from the rock mass can be neglected, $Q=0$ (see Section 5.5). However, volumetric capacity of gas is much smaller than rock's (The $\chi$-ratio is very small, see Section 5.3), and the significance of heat transfer in a gas-filled cavern must be discussed.

\subsection{An example}

An example is provided by ${ }^{34}$ Heath and Benefield; a cycle lasting 6 months was applied in a cavern; pressure dropped from 16.2 $\mathrm{MPa}$ to $5.6 \mathrm{MPa}$, then returned to $16.2 \mathrm{MPa}$. The dotted line on Fig. 13 shows the computed adiabatic evolution. It is clear that neither the adiabatic nor the isothermal assumptions (see Figs. $6,7,8$ ) fit the actual behavior of a gas-storage cavern; heat transfer from the rock mass must be taken into account.

\subsection{Energy equation in a gas cavern}

When cavern shape is known, precise computation of the heat flux from the rock mass $(Q)$ can be done through numerical computations. However, when rapid injections/withdrawals are considered, simplifications can be made. Consider a $\delta t$-long rapid gas withdrawal - for instance, $\delta t=4$ days. Pressure and temperature both drop. During such a short period, temperature changes are not given enough time to penetrate into the rock mass much deeper than $d=\sqrt{k_{R} t}$, where $k_{R}=3 \times 10^{-6} \mathrm{~m}^{2} / \mathrm{s}$ is the thermal diffusivity of salt, or $d \approx 1 \mathrm{~m}$. From the perspective of thermal conduction, cavern walls, as noted by ${ }^{36}$ Crotogino et al., 2001 and ${ }^{37}$ Krieter, 2011, can be considered as the sum, $\Sigma$, of small flat surfaces (a simplified description of small surfaces whose radius of curvature is not smaller than $d$.) $\Sigma$ is the effective area of cavern walls - a notion that depends on the duration of the gas withdrawal. 
When a constant temperature, $T_{0}$, is applied at the flat surface of a semi-infinite space, the heat flux is $Q=\Sigma K_{R}\left(T_{\infty}-T_{0}\right) / \sqrt{\pi k_{R} t}$. Note that when, instead of a flat surface, an idealized spherical cavern with radius $a$ is considered, the flux is $Q=\Sigma K_{R}\left(T_{\infty}-T_{0}\right) /\left(1 / a+1 / \sqrt{\pi k_{R} t}\right) \quad[\ln$ software programs used by the cavern industry, a spherical cavern whose volume equals the actual cavern volume often is considered; its surface (together with the heat resistance coefficient $\bar{H}$, see Section 5.1) is selected to fit the actual measurements. Neither this procedure nor the procedure suggested in this paper can account both for short and long periods of time. The procedure used in this paper allows using the results of sonar surveys, which provide a good picture of cavern shape]. When gas temperature is not constant, $T=T(t)$, the flux can be expressed through a convolution:

$$
Q(t)=K_{R} \Sigma \int_{0}^{t} \frac{\dot{T}(\tau)}{\sqrt{\pi k_{R}(t-\tau)}}
$$

After some simplification, the energy equation can write:

$$
\frac{\gamma}{\gamma-1} \frac{P(t)}{T(t)} \dot{T}(t)-\dot{P}(t)=-\frac{\Sigma}{V} \frac{K_{R}}{\sqrt{\pi k_{R}}} \int_{0}^{t} \frac{\dot{T}(\tau)}{\sqrt{t-\tau}} d \tau+\frac{<\dot{m}>}{V} C_{P}\left(T_{i n j}-T\right)
$$

When gas is withdrawn $(\dot{m}<0)$, temperature evolution results from gas expansion $(\dot{P}<0)$, whose effects are mitigated by the heat flux from the rock mass (right-hand side). Beside initial conditions, $P_{0}$ and $T_{0}$, only two physical constants appear in this equation, $\gamma=C_{P} / C_{v}$ and $\Sigma K_{R} / V \sqrt{\pi k_{R}}$. The adiabaticity index, $\gamma=C_{P} / C_{v}$, equals $\gamma=1.4$ (air, hydrogen) or $\gamma=1.3$ (methane). A comparison of temperature evolution when air, methane or hydrogen is stored can be found in ${ }^{38}$ Nieland, 2008, ${ }^{6}$ Schlichtenmayer and Bannach, 2015 and ${ }^{39}$ Louvet et al., 2017. The influence of rock thermal properties occurs through the parameter $K_{R} / \sqrt{\pi k_{R}}$, whose value typically is $1800 \mathrm{~W} \times \mathrm{s}^{1 / 2} / \mathrm{m}^{2}$ (see Table 2 ).

The ratio $V / \Sigma$ depends on cavern shape and is proportional to cavern size. This is the parameter susceptible of the largest variations. Following a gas withdrawal, the temperature drop is larger in a bigger cavern. ${ }^{41}$ Staudtmeister et al., 2010 , suggest $V / \Sigma=8$ $12 \mathrm{~m}$; larger values are found in a large cavern when the height/diameter ratio is close to 1. In an idealized spherical cavern with radius $a$, for instance, $V=525,000 \mathrm{~m}^{3}, a=50 \mathrm{~m}$ and 
$V / \Sigma=a / 3=17 \mathrm{~m} .{ }^{44}$ Rokahr et al., 2011, mention that "the ratio $V / \Sigma$ is usually less than $10 \mathrm{~m}$ for caverns in salt domes because they are often shaped long and thin" (p. 194).

\subsection{Influence of the shape factor}

An interesting example of the influence of the shape factor $(\Sigma / V)$ was described by ${ }^{15}$ Quast (1983). The Huntorf CAES storage, mentioned in Section 3.2, consists of two caverns, NK1 and NK2, whose volumes accessible to air are $V_{1}=140000 \mathrm{~m}^{3}$ and $V_{2}=170000 \mathrm{~m}^{3}$, respectively (Fig. 14). Their pressure varies between 4.3 $\mathrm{MPa}$ and $7 \mathrm{MPa}$; maximum pressure rate during air withdrawal is $\dot{P}=1.5 \mathrm{MPa} / \mathrm{hr}$. During operation, the two caverns are connected at ground level, which means that their pressures are almost perfectly equal. One can expect that the inventory is larger in the bigger cavern (NK2). ${ }^{15}$ Quast (1983) mentions that this was not observed when operating the caverns (injected masses were similar in the two caverns) as gas temperature increases more slowly in the NK1 cavern whose effective surface is larger.

\subsection{The case of the Melville cavern}

Instead of $P, T$ in Eq. (18), $m$ and $T$ can be selected as the main variables, $m=P V_{0} / R T$ :

$$
m C_{v} \dot{T}-\dot{m} r T=-\frac{\Sigma K_{R}}{\sqrt{\pi k_{R}}} \int_{0}^{t} \frac{\dot{T}(\tau)}{\sqrt{t-\tau}} d \tau+<\dot{m}>C_{P}\left(T_{i n j}-T\right)
$$

This integro-differential equation was tested against a withdrawal test $(\dot{m}<0)$ described by ${ }^{46}$ Crossley, 1996 . The test was performed in the Regina \#5 natural-gas storage cavern at Melville (Canada). The measured flow rate, cavern pressure and temperature are drawn on Fig. 15. The withdrawal period was 5-days long. For computations ( ${ }^{47}$ Djizanne et al., 2014), the following values were selected: $K_{R}=6 \mathrm{~W} / \mathrm{m} / \mathrm{K}, \gamma=1.305$, and $V=46,000 \mathrm{~m}^{3}$. Cavern shape was unknown, and the surface of the cavern walls was selected to be twice the surface of a sphere whose volume equals the actual cavern volume, $V / \Sigma=3.6 \mathrm{~m}$. Note that slightly before the end of the withdrawal phase, gas begins to warm, as the withdrawal flowrate and the heat capacity of the gas mass are small, whereas the heat flux from the 
rock mass is high. A similar observation was made by ${ }^{45}$ Crotogino et al. (2001): "An interesting effect occurs when the air is expanded to atmospheric pressure [in the Huntorf caverns, see Sections 3.2 and 5.9]: the pressure drop initially results in the expected cooling of the air, but after reaching a minimum, the temperature rises again" (p. 355).

\subsection{Gas warming in a shut-in cavern}

In this section, we discuss a case similar to that discussed in Section 5.4. At $t=0$, the cavern temperature, which was $T=T_{\infty}$, is decreased abruptly to $T=T_{\infty}-T_{0}$, and the cavern is shut in $(\dot{m}=0)$ :

$$
m_{0} C_{v} \dot{T}(t)=-\frac{\Sigma K_{R}}{\sqrt{\pi k_{R}}}\left[\frac{T_{0}-T_{\infty}}{\sqrt{t}}+\int_{0}^{t} \frac{\dot{T}(\tau)}{\sqrt{(t-\tau)}} d \tau\right]
$$

As in Section 5.3, two characteristic times can be defined: $a^{2} / k_{R}$ and $a^{2} / k_{R} \chi, \chi=\rho_{R} C_{P}^{R} / \rho_{g} C_{P}^{g}$, which are relative to the rock mass and the gas body, respectively. The latter characteristic time is much shorter than in the case of a liquid, and thermal equilibrium with the rock mass at the cavern wall is reached rapidly. However, in the first years following leaching completion, temperature at the cavern wall is much colder than the geothermal temperature at the cavern depth. The former characteristic time suggests that equilibrium temperature (between gas and rock wall) slowly increases with time ( ${ }^{8}$ Fosse and Røvang, 1998).

\subsection{Thermodynamic evolution during a fast, small temperature change}

When withdrawal is considered, a simplified solution of Eq. (18) can be reached as follows. It is assumed that temperature decreases by a small amount, $\delta T<0$ (when compared to the initial temperature $T_{0}$ ), during a $\delta t$-long period and that temperature rate is constant; $\delta T / T$ is not very different from $\delta T / T_{0}$. (When $\delta T=10^{\circ} \mathrm{C}$, the relative error is $3 \%$.) Then, Eq. (18) can be solved as follows:

$$
\frac{\delta P}{\delta T}=\left(\frac{4}{3} \frac{\Sigma}{V} \frac{K}{\sqrt{\pi k}}(\delta t)^{1 / 2}+\frac{\gamma}{\gamma-1} \frac{P_{0}}{T_{0}}\right)
$$


Equation (21) proves that the temperature drop (for a given pressure drop) is larger when the initial pressure, $P_{0}$ is smaller when the pressure drop is faster and ratio $\Sigma / V$ is smaller. This solution holds when $\delta T$ and $\delta P$ are not too large. For instance, $\gamma=1.4$ (air), $T_{0}=310 \mathrm{~K}$, $K_{R} / \sqrt{\pi k_{R}}=1800 \mathrm{~W} / \mathrm{s}^{1 / 2} m^{2}$ lead to:

$$
\frac{\delta P[\mathrm{MPa}]}{\delta T\left[{ }^{\circ} \mathrm{C}\right]}=0.072 \frac{\Sigma}{V} \delta t^{1 / 2}\left[\mathrm{hr}^{1 / 2}\right]+0.011 \mathrm{P}_{0}[\mathrm{MPa}]
$$

For instance, $P_{0}=7 \mathrm{MPa}, \Sigma / V=0.1 \mathrm{~m}^{-1}$, and $\delta T / \delta P=9.5^{\circ} \mathrm{C} / \mathrm{MPa}$. Such a temperature drop can have significant structural consequences: tangential tensile stresses are generated at the cavern wall, and fracturing may occur. (This topic has been studied by many authors.) Orders of magnitude can be reached as follows. Consider the case of an idealized cylindrical cavern with radius $a$, cavern pressure $P_{c}$, and geostatic pressure, $P_{\infty}$. Cavern pressure is lowered from $P_{c}$ to $P_{c}-\delta P$. The worst case (largest temperature drop) is reached when gas evolution is isentropic, $\delta P / \delta T=\gamma P_{0} /(\gamma-1) T_{0}$. Salt behavior is elasto-thermo-viscoplastic; a uniaxial formulation is: $\dot{\varepsilon}=\dot{\sigma} / E-\alpha_{R} \dot{T}+A \sigma^{n}$. It is assumed that before the pressure drop, steadystate viscoplastic behavior is reached, and the vertical stress is $\sigma_{z z}(a)=-\left(P_{\infty}-P\right) / n\left({ }^{48} \mathrm{~W}\right.$ ang et al., 2015). However, the effect of viscoplastic deformation is to lower deviatoric stresses and, considering the thermo-elastic deviatoric stresses is on the safe side. The vertical tangential stress immediately after a gas drop can written

$$
\sigma_{z z}(a)+P=-\frac{P_{\infty}-P}{n}+\delta P-\frac{\bar{E} \bar{\alpha}}{1-\bar{v}} \delta T=-\frac{P_{\infty}-P}{n}+\delta P\left(1-\frac{\bar{E} \bar{\alpha}}{1-\bar{v}} \frac{\gamma-1}{\gamma} \frac{T_{0}}{P_{0}}\right)
$$

Tensile effective stresses, $\sigma_{z z}(a)+P>0$, can appear $\left(\bar{E}=25 \mathrm{GPa}, \bar{\alpha}=4 \times 10^{-4} /{ }^{\circ} \mathrm{C}, \quad \bar{v}=0.3\right.$, $\gamma=1.4, \mathrm{~T}_{0}=300 \mathrm{~K}$ and $\mathrm{P}_{0}=7 \mathrm{MPa}$ are typical of an air storage, and $\bar{E} \bar{\alpha} T_{0}(\gamma-1) / \gamma P_{0}(1-\bar{v})$ is much larger than 1.) and can lead to fracturing ( ${ }^{49}$ Sicsic and Bérest, 2014).

\section{Gas flow in the wellbore; hydrate formation}

Especially during rapid injection or withdrawal, gas temperature and pressure are not identical at ground level $(z=0)$ and at the cavern entrance $(z=H)$ because of head losses and gravity forces. In the case of gas production, this problem was discussed through numerical 
computations (for instance, by ${ }^{50}$ Kabir et al., 1996). When gas contains water vapor during withdrawal, hydrates can form in the wellbore when a certain relation between gas pressure, temperature and moisture content is met, $c_{v}>c_{\text {hydrate }}\left(P_{w}, T_{w}\right)$. Hydrates are harmful for surface equipment and pipes. Most often, an inhibitor (methanol) is injected at shallow depth in the wellbore to prevent hydrate formation. This operation is costly, and various solutions have been proposed in the literature to hinder hydrate formation $\left({ }^{51}\right.$ Réveillère et al., 2016). In fact, thermodynamic evolution can be computed when several simplifications are accepted. The average gas speed is in the $u=1-15 \mathrm{~m} / \mathrm{s}$ range; the wellbore diameter is $D$ $=0.2-0.3 \mathrm{~m}$; and the gas viscosity is $\bar{v}_{g}=10^{-7} \mathrm{~m}^{2} / \mathrm{s}$ (when gas density is $\rho_{g}=200 \mathrm{~kg} / \mathrm{m}^{3}$ ). The Reynolds number, $R=D u / \bar{V}$, is larger than $10^{4}$, gas flow is turbulent, and the gas speed is uniform, $u=u(z, t)$, in any horizontal section (except for a thin boundary layer at the casing wall). When the gas speed is $u=10 \mathrm{~m} / \mathrm{s}, 100 \mathrm{~s}$ are needed for gas to cross through a wellbore that is $H=1000-\mathrm{m}$ long. During such a period of time, cavern pressure and temperature are not given time enough to change significantly: steady-state is reached, and mass conservation can be written $\dot{m}=S \rho(z) u(z)$, where $\dot{m}$ is a slowly varying function of time, and $S$ is the wellbore cross-sectional area. (In fact, wellhead temperature increases first during a withdrawal, as the cavern gas is warmer than that at ground level $\left(^{52} \mathrm{Grosswig}\right.$ et al., 2001), a transient phenomenon.) Along the wellbore, rock temperature does not equal gas temperature, and heat transfer takes place. However, during a one-day period during which $10 \%$ of the gas inventory is withdrawn, rock temperature experiences significant changes in a cylinder whose radius is $a=\sqrt{k_{R} t}=0.5 \mathrm{~m}$ and whose height is $H=1000 \mathrm{~m}$. Its thermal capacity is $\pi a^{2} H \rho_{R} C_{P}^{R}$, where $\rho_{R} C_{P}^{R}=2 \times 10^{6} \mathrm{~J} / \mathrm{m}^{3} /{ }^{\circ} \mathrm{C}$. The cavern volume is $V_{c}=$ $500000 \mathrm{~m}^{3}$, of which $\delta V_{c}=10 \%$ is withdrawn; the heat capacity of the withdrawn natural gas is $\delta V_{c} \rho_{g} C_{P}^{g}$, where $\rho_{g} C_{P}^{g}=4 \times 10^{5} \mathrm{~J} / \mathrm{m}^{3} /{ }^{\circ} \mathrm{C}$ (Gas pressure is $P_{C}=20 \mathrm{MPa}$.), and $\pi a^{2} H \rho_{R} C_{P}^{R}$ $=1.510^{9} \mathrm{~J} / \mathrm{m}^{3} /{ }^{\circ} \mathrm{C}$ is much smaller than $\delta V_{c} \rho_{g} C_{P}^{g}=2.2510^{11} \mathrm{~J} / \mathrm{m}^{3} /{ }^{\circ} \mathrm{C}$. The change in rock temperature (less than a few dozen ${ }^{\circ} \mathrm{C}$ ) is much larger than the gas temperature change, and gas flow is considered as adiabatic. The set of equations for speed, density, pressure and entropy can be written

$$
\dot{m}=S \rho_{w}(u) u
$$




$$
\begin{gathered}
\frac{\gamma}{\gamma-1} \frac{P_{w}(u)}{\rho_{w}(u)}+\frac{u^{2}}{2}-g z=I \\
\frac{1}{\rho_{w}(u)} \frac{d P_{w}[u(z)]}{d z}+u \frac{d u}{d z}-g=-\varepsilon F u^{2} \\
u \frac{s_{w}[u(z)]}{d z} \geq 0
\end{gathered}
$$

Equation (23) reflects mass conservation. Equation (24) is the enthalpy equation, where $g$ is gravity acceleration, and $I$ is a constant along a flow path that can be computed at $z=0, u=$ $u_{0}$ or at $z=H, u=u_{c}$. Equation (25) is the momentum equation, where $F u^{2}>0$ is the head loss per unit of length, $F$ is a function of duct diameter, wall roughness, etc., and $\varepsilon= \pm 1=\operatorname{sgn}(u)$. Entropy inequality, Eq. (26), also can be written as follows: $d h(s, \rho)=T d s+d P /\left.d \rho\right|_{s} d \rho, d P /\left.d \rho\right|_{s}=c^{2}$, where $c$ is the velocity of sound $(c=\sqrt{\gamma r T}$; for methane, $c=450 \mathrm{~m} / \mathrm{s}$ is typical), and $d h=u d u-g d z$ or $T d s=\left(c^{2}-u^{2}\right) d u / u+g d z$. The gas speed must be smaller than the velocity of sound, a condition that is satisfied when $u$ equals a few dozen $\mathrm{m} / \mathrm{s}$. In the case of a blowout, $u$ can equal $c$; this case is discussed in ${ }^{53}$ DjakeunDjizanne et al., 2013. Only standard gas speed during operation are considered here. From Eqs. $(23,24,25), P$ and $\rho$ can be eliminated, leading to

$$
-\frac{\gamma+1}{2(\gamma-1)}+\left[\frac{g z+I}{u^{2}}+\frac{1}{\gamma-1}\left(\frac{g}{u}-\gamma \varepsilon F u\right) \frac{d z}{d u}\right]=0
$$

When gravity is disregarded $(g=0)$, this equation can be solved easily $\left({ }^{53}\right.$ Djakeun-Djizanne et al., 2013):

$$
\left[-\frac{\gamma+1}{4(\gamma-1)} \log ^{2}-\frac{I}{v^{2}}\right]_{v=u_{0}}^{v=u}-\frac{\gamma}{\gamma-1} \varepsilon F z=0
$$

When gravity is taken into account, the solution can be written

$$
\left[(\boldsymbol{g} z(\boldsymbol{u})+\boldsymbol{I})\left(\frac{\boldsymbol{u}}{\sqrt{1-\gamma \mathcal{E} \boldsymbol{F} u^{2} / g \mid}}\right)^{\gamma-1}\right]_{\substack{u=u_{0} \\ z=0}}^{u(z)}=\frac{\gamma+1}{2} \int_{u_{0}}^{u(z)}\left(\frac{v}{\sqrt{\left|1-\gamma \mathcal{E} \boldsymbol{F} v^{2} / g\right|}}\right)^{\gamma-1} \frac{v d v}{1-\gamma \mathcal{E} \boldsymbol{F} v^{2} / g}
$$

from which $u(z), \rho_{w}(u) T_{w}(u)$ and $P_{w}(u)$ can be inferred. The withdrawal case $(\varepsilon=-1, \dot{m}<0, u<0)$ is simple when $\dot{m}$ is fixed, and boundary conditions $\rho(H)=\rho_{\mathrm{c}}, P(H)=P_{c}$, 
$T(H)=T_{c}$ and $I=I_{c}$ are known at cavern depth. Computations are straightforward The moisture content such that hydrate can form is a function of pressure and temperature. When moisture content at the cavern top (from which gas is withdrawn) is known, hydrate formation at shallow depth in the wellbore can be discussed. Computations allow discussion of hydrate formation, which is a function of water vapor concentration in the cavern, and gas pressure and temperature in the well $\left({ }^{54} \mathrm{Klafki}\right.$ et al., 2003). The case of gas injection ( $\varepsilon=1, \dot{m}>0, u>0$ ) is slightly more complicated: $P(H)=P_{c}$ is known, but neither $T$ nor $\rho$ is continuous through $z=H$; a second boundary equation (at ground level, $z=0$ ) must be used. In addition, $d u / d z$ can vanish when $F u^{2}=\gamma g$, which means that $u=u(z)$ is not a monotonous function of $z$.

\section{Conclusion}

Various aspects of the thermodynamic behavior of gas- and liquid-filled caverns were discussed. In the case of liquid-filled caverns, onset of natural convection is certain. Rapid pressure changes (1 day) lead to small adiabatic temperatures changes. Conversely, thermal equilibrium between the cavern liquid and the rock mass is reached after a long period of time, raising the problem of long-term behavior after cavern decommissioning. The heat capacity of gas-filled caverns is much smaller, and most features of thermodynamic behavior are different. Natural convection is not always present, and the reasons for this are not perfectly clear, although water vapor distribution in the cavern might be an important factor. Gas evolution is not adiabatic, even during short injections/withdrawals. During withdrawal, gas is cooled in the cavern and in the wellbore, an evolution that can be captured through simple equations. Gas cooling leads to possible tensile fracture creation at the cavern wall and hydrate formation at wellbore top. Most of these features can be captured by simple models. Advances in the understanding of cavern behavior will rely mostly on field data, which are relatively scarce.

\section{Acknowledgements}

Analysis of the incidents in this paper was funded in part by the French Agence Nationale de la Recherche (ANR) in support of the FluidStory Project, devoted to storage of $\mathrm{O}_{2}$ and $\mathrm{CO}_{2}$ in 
salt caverns. This project includes researchers from Armines, Areva- $\mathrm{H}_{2} \mathrm{Gen}, \mathrm{BRGM}, \mathrm{Brouard}$ Consulting, Geostock, Geogreen and Ecole Polytechnique. Special Thanks to M. Pottier and K. Sikora.

\section{References}

\section{SMRI Reports are available at: solution.mining.org}

[1] Brouard B. Sur le comportement des cavités salines. Etude théorique et expérimentation in situ. [in French] PhD Thesis. Ecole Polytechnique

[2] Karimi-Jafari M. Sur le comportement transitoire des cavités salines profondes. Etude numérique et interprétation des essais in situ. [in French] PhD Thesis. Ecole Polytechnique.

[3] Banach A, Klafki M. Stassfurt shallow cavern abandonment field test. Report 2009-1 prepared for the Solution Mining Research Institute,2009:77p.

[4] Klafki M, Wagler T, Grosswig S, Kneer A. Long-term downhole fibre optic temperature measurements and CFD modeling for investigation of different gas operating modes. In: Proceedings SMRI Fall Meeting, Chester; 5-8 October 2003. p.180-189.

[5] Gas Encyclopedia Air Liquide, visited on January 18, 2019.

[6] Schlichtenmayer M, Bannach A; Amro M, Freese C (subcontractors). Renewable Energy Storage in Salt Caverns - A comparison of Thermodynamics and Permeability between Natural Gas, Air and Hydrogen. Report 2015-1 prepared for the Solution Mining Research Institute, 2015.

[7] Walden S, Gaertner R, Schultz KF. Thermal influences on Salt Formation during Solution Mining in the Case of a Gas Storage Cavern in Bremen, Germany. In: Proceedings SMRI Spring Meeting, Orlando; 23-25 April 2001. p. 375-392.

[8] Fosse AP, Røvang LB. Verifying Established Initial Gas Temperature Distribution in Caverns. In: Proceedings SMRI Spring Meeting, New Orleans; 19-22 April 1998. p.126-142.

[9] Sivoukhine. Cours de Physique générale, Tome II, Thermodynamique et Physique moléculaire. Moscou, Mir Editions;1982. [in French].

[10] Landau L., Lifschitz E. Mécanique des Fluides. Moscou, Mir Editions ;1971. [in French]. 
[11] Louvet F, Charnavel Y, Portenabe JC. Moisture content of Gas in Salt Caverns Surface Measurements. In: Proceedings SMRI Fall Meeting, Belfast; 24-26 September 2018. p.17-30.

[12] Köckritz V, Walden S. Studies into Thermodynamics and Moisture Development in Gas Storage Caverns. In: Proceedings SMRI Fall Meeting, Hannover; September1994. 17p.

[13] Thaule SB, Gentzsch L. Experience with Thermophysical Modelling of Gas Cavern Operations in Etzel. In: Proceedings of SMRI Fall Meeting, Hannover; September 1994.

[14] Köckritz V, Walden S, Lǿvland J. Theoretical and experimental investigations on the water vapour content in gas caverns. In: Proceedings SMRI Fall Meeting, Cleveland; 20-23 October 1996. p.353-373.

[15] Quast P. L'installation de Huntorf : plus de trois années de fonctionnement de cavernes à air comprimé. [in French]. Annales des Mines. 1983;5-6:93-102.

[16] Skaug N, Ratigan J, Thompson M. Natural Gas Cavern Inventory assessment - A New approach. In: Proceedings SMRI Spring Meeting, Grand Junction, 26-27 April 2010. p.303312.

[17] Berger H, Zündel F, Walden S. Water in Gas Storage Caverns - Problems and Solutions. In: Proceedings SMRI Fall Meeting, Bad Ischl; 6-9 October 2002. p.53-64.

[18] Istvan J, Cavern evaluation by means of Temperature and Pressure Profile Surveys. In: Proceedings SMRI Spring Meeting, Houston; 14-17 April 1996. 9p.

[19] Schneider R, Grosswig St, Hurtig E, Muecke L. Leak detection of the fluid level in the annulus in the Kiel underground storage facility (Germany) using Fiber optic temperature measurements. In: Proceedings SMRI Fall Meeting, Bad Ischl; 6-9 October 2002. p.251-269.

[20] Karimi-Jafari M, Réveillère A, Frassy C. Cavern Integrity and Performance Management at Geomethane Underground Storage. In: Proceedings SMRI Fall Meeting, Groningen; 29-30 September 2014. p.13-30

[21] Krieter M, Gotthardt K. The in-situ Sampling of Gas in Caverns and the Development of Software to avoid Hydrates and reduce the Admixture of Inhibitors. In: Proceedings SMRI Fall Meeting, Santander; 28-29 September 2015. p.187-196.

[22] Osnes JD, Kerry KL, Ratigan JL, Meece MW, Thompson M, Spencer GW. A case history of the threaded coupling production casing failure in gas caverns - Part 1: Detection and 
geomechanical analysis. In: Proceedings of the SMRI Fall Meeting, Halifax; 8-9 October 2007. p.41-70

[23] Reitze A, von Tryller, H. The Influence of Physical Conditions Inside a Cavern on Execution and Evaluation of Sonar Surveys. In: Proceedings SMRI Spring Meeting, Syracuse; 17-20 April 2005. p. 279-292.

[24] Kushnir R, Dayan A, Ullmann A. Temperature and pressure variations within compressed air energy storage caverns. Int. J. Heat and Mass Transfer. 2012;55:5616-5630.

[25] Bérest P, Bergues J, Brouard B. Review of static and dynamic compressibility issues relating to deep underground salt caverns. Int. J. Rock Mech. Min. Sci.1999;36:1031-1049.

[26] Bérest P, Brouard B, Gharbi H. Rheological and geometrical reverse creep in salt caverns. In: Proceedings Mech. Beh. Salt VIII. Rapid City; 26-28 May 2015. p.199-208.

[27] Karimi-Jafari M, Bérest P, Brouard B. Thermal Effects in Salt Caverns. In: Proceedings SMRI Spring Meeting, Basel; 29 April -2 May 2007. p. 165-177.

[28] Khaledi K., Mahmoudi E, Datcheva M., Schantz E. Analysis of compressed air storage caverns in rock salt considering thermo-mechanical cyclic loading. Environmental Earth Sci.2016;75(15):1-17.

[29] Brouard B, Bérest P, de Greef V, Beraud JF, Lheur C., Hertz E. Creep closure rate of a shallow salt cavern at Gellenoncourt, France. Int. J. Rock Mech. Min. Sci. 2013;62:42-50.

[30] Van Sambeek L, Bérest P, Brouard B. Improvements in Mechanical Integrity Tests for Solution-mined caverns used for mineral production or liquid-product storage. Report 20051 prepared for the Solution Mining Research Institute;2005.

[31] Bérest P, Bergues J, Brouard B, Durup JG, Guerber B. A salt cavern abandonment test. Int. J. Rock Mech. Min. Sci. 2001;38:357-368.

[32] Bérest $P$, Brouard $B$, Hertz $E$, Lheur $C$, Hévin $G$, de Laguérie $P$, Hardy JM. Cavern abandonment: Three in situ tests. In: Proceedings SMRI Meeting, Avignon; 30 September-1 October 2013. p.23-36. 
[33] Thoraval A, Lahaie F, Bérest P, Brouard B. A generic model for predicting the behaviour of storage caverns in salt to help evaluate and prevent the risks associated with their abandonment. Int. J. Rock Mech. Min. Sci. 2015;77:44-59.

[34] Gatelier N, You Th, Bérest P, Brouard B. Adiabatic temperature changes in an oil-filled cavern. In: Proceedings SMRI Fall Meeting, Galveston; 13-14 October 2008. p.81-103.

[35] Heath SA, Benefield RK. High Frequency Gas Storage Operations Using Downhole Instrumentation. In: Proceedings SMRI Fall Meeting, Leipzig; 3-6 October 2010. p.109-124.

[36] Crotogino F, Mohmeyer KU, Scharf R. Huntorf CAES: More than 20 Years of Successful Operation. In: Proceedings SMRI Spring Meeting, Orlando; 23-24 April 2001. p.351-362.

[37] Krieter M. Influence of gas cavern's surface area on thermodynamic behaviour and operation. In: Proceedings SMRI Fall Meeting, York; 3-4 October 2011. p.179-184.

[38] Nieland JD. Salt cavern thermodynamics-Comparison between hydrogen, natural gas, and air storage. In: Proceedings SMRI Fall Meeting, Galveston; 13-14 October 2008. p.215234.

[39] Louvet F., Charnavel Y., Hévin G. Thermodynamic studies of hydrogen storage in salt caverns. In: Proceedings SMRI Spring Meeting, Albuquerque; 23-26 April 2017. p.338-352.

[40] Pellizzaro C, Bergeret G, Leadbetter A, Charnavel Y. Thermomechanical behavior of Stublach gas storage caverns. In: Proceedings SMRI Fall Meeting, York; 3-4 October 2011. p.161-178.

[41] Staudtmeister K, Zapf D, Leuger B. The influence of different loading scenarios on the thermo-mechanical behavior of a gas storage cavern. In: Proceedings SMRI Spring Meeting, Galveston; 18-19 April 2011. p. 83-97.

[42] Blanco Martin L, Rutqvist JT, Birkholzer J, Wolters R, Lux KH. Coupled modelling of the thermal simulation for drift emplacement underground test. In: Proceedings Mech. Beh. Salt VIII. Rapid City, 26-28 May 2015:381-387.

[43] Brouard Consulting, Paris. LOCAS. A software dedicated to salt caverns. 2019.

[44] Rokahr R, Staudtmeister K, Zapf D. Rock mechanical design for a planned gas cavern field in the Preesall Project Area, Lancashire, UK. In: Proceedings SMRI Fall Meeting, York; 34 October 2011. p.189-204. 
[45] Crotogino F, Mohmeyer KU, Scharf R. Huntorf CAES: More than 20 years of successful operation. In: Proceedings SMRI Spring Meeting, Orlando; 23-24 April 2001. p.351-362.

[46] Crossley NG. Salt cavern Integrity Evaluation Using Downhole Probes. A Transgas Perspective. In: Proceedings SMRI Fall Meeting, Cleveland; 20-23 October 1996. p.21-54.

[47] Djizanne $H$, Bérest $P$, Brouard $B$. The mechanical stability of a salt cavern used for compressed air energy storage (CAES). In: Proceedings SMRI Spring Meeting, San Antonio; 56 May 2014. p.31-52.

[48] Wang L, Bérest P, Brouard, B. Mechanical Behavior of Salt Caverns: Closed-Form Solutions vs Numerical Computations. Rock Mech. and Rock Eng. 2015;48,6:2369-2382.

[49] Sicsic P, Bérest P. Thermal Cracking following a blowout in a gas storage cavern. Int. J. Rock Mech. Min. Sci. 2014;71:320-329.

[50] Kabir CS, Hasan AS, Jordan DL, Xiao Wei Wang. A wellbore/reservoir simulator for testing gas well in high temperature reservoirs. SPE formation evaluation. June 1996.

[51] Réveillère A, Azimi B, Arnold C. Prevention of stored gas humidification: lessons learnt and review of possibilities. In: Proceedings SMRI Spring Meeting, Galveston; 25-26 April 2016. p.33-12.

[52] Grosswig S., Hurtig E., Kühn K. Distributed fiber-optic temperature sensing techniques (DTS) for surveying caverns and brine pipelines. In: Proceedings SMRI Fall Meeting, Albuquerque; 7-10 September 2001. p.284-293.

[53] Djizanne H, Bérest P, Brouard B, Frangi A. Blowout in Gas Storage Caverns. Oil \& Gas Science and Technology - Rev. IFP Energies Nouvelles. 2014;69,7:1251-1267.

[54] Klafki M, Bannach A, Wagler T, Pusch G, Meyn V. State of the Art Review of Hydrate Formation Potential Associated with Natural Gas Storage Operations in Salt Caverns. Report 2003-1 prepared for the Solution Mining Research Institute, 2003.

\section{Table headings}

Table 1. Gas thermal constants, from ${ }^{5}$ Gas Encyclopedia, Air Liquide. Constants are measured at $\theta=25^{\circ} \mathrm{C}$ and $P_{N}=0.10325 \mathrm{MPa}$. 
Table 2. Values of $K_{R} / \sqrt{\pi k_{R}}$

\section{Figure captions}

Figure 1. Temperature profile along the vertical axis of the EZ53 brine cavern from the Etrez site in France ( ${ }^{1}$ Brouard, 1998 , courtesy of Storengy).

Figure 2. As-computed convection cells in the EZ53 cavern, assuming axisymmetry. Left: iso-values of the streamline function; right: velocity magnitude ( ${ }^{2}$ Karimi-Jafari, 2007).

Figure 3. Temperature profile along the vertical axis of symmetry in a brine cavern ('Banach and Klafki, 2009).

Figure 4. Temperature profile in the S107 natural gas cavern, Stassfurt, Germany (left); cavern shape selected for numerical computations (right) (after ${ }^{4}$ Klafki et al., 2003).

Figure 5. Temperature profile in a cavern at Etzel, Germany; roof depth is slightly more than $1200 \mathrm{~m}$, and the gas interface is slightly above $1500 \mathrm{~m}\left({ }^{13}\right.$ Thaule and Gentzsch, 1994).

Figure 6. The cavern profile (1) is drawn on the left side of each picture. In the left illustration, temperature profiles before (5) and after $(2,3,4)$ three consecutive withdrawals are represented; the right illustration represents how temperature reaches thermal equilibrium after the withdrawals are completed $(2,3)\left({ }^{4} \mathrm{Klafki}\right.$ et al., 2003).

Figure 7. Gas flowrates (above); for air, $1 \mathrm{Nm}^{3}=1.29 \mathrm{~kg}$. Temperature profiles along a vertical axis in the NK1 cavern of the Huntorf CAES after injections and withdrawals (below) ( ${ }^{15}$ Quast, 1983).

Figure 8. Enterprise Cavern 1 (left) - At a 3751-ft (1144-m) depth, gas pressure was decreased from 2728 psi (18.8 MPa) to 1994 psi (13.7 MPa) between April 2009 and May 2009 ( ${ }^{16}$ Skaug et al., 2010); (right) a tentative explanation.

Figure 9. Temperature profile in an anonymous gas cavern: the temperature gradient in the upper part of the cavern is $G=6 \times 10^{-3 \circ} \mathrm{C} / \mathrm{m}$; it is negative above the sump. (After ${ }^{17}$ Berger et al., 2002). 
Figure 10. Temperature evolution in an $8000-\mathrm{m}^{3}$ cavern after solution mining is completed (Courtesy of Storengy).

Figure 11. Pressure evolution in three caverns from the same site whose sizes are different ( ${ }^{29}$ Van Sambeek et al., 2005; courtesy of Storengy).

Figure 12. Pressure and Temperature evolutions in an oil cavern during injections/withdrawals ( ${ }^{34}$ Gatelier et al., 2008).

Figure 13. Cavern temperature as a function of cavern pressure during a cycle in a gas storage cavern in the Gulf of Mexico. The blue dotted line represents the computed adiabatic behavior $P^{a d} / P_{0}=\left(T^{a d} / T_{0}\right)^{1-1 / \gamma}$ (after ${ }^{35}$ Heath and Benefield, 2010).

Figure 14. Vertical cross sections of Huntorf NK1 (left) and NK2 (right) caverns. From ${ }^{45}$ Crotogino et al. 2001.

Figure 15. Melville Cavern: Gas withdrawal rate, pressure and temperature evolutions as observed (after ${ }^{46}$ Crossley, 1996) and as computed: $1 \mathrm{MSCFH}=28,317 \mathrm{Nm}^{3} / \mathrm{hr}$, $1 \mathrm{MPa}=145 \mathrm{psig}$ and $20^{\circ} \mathrm{C}=68^{\circ} \mathrm{F}$. 

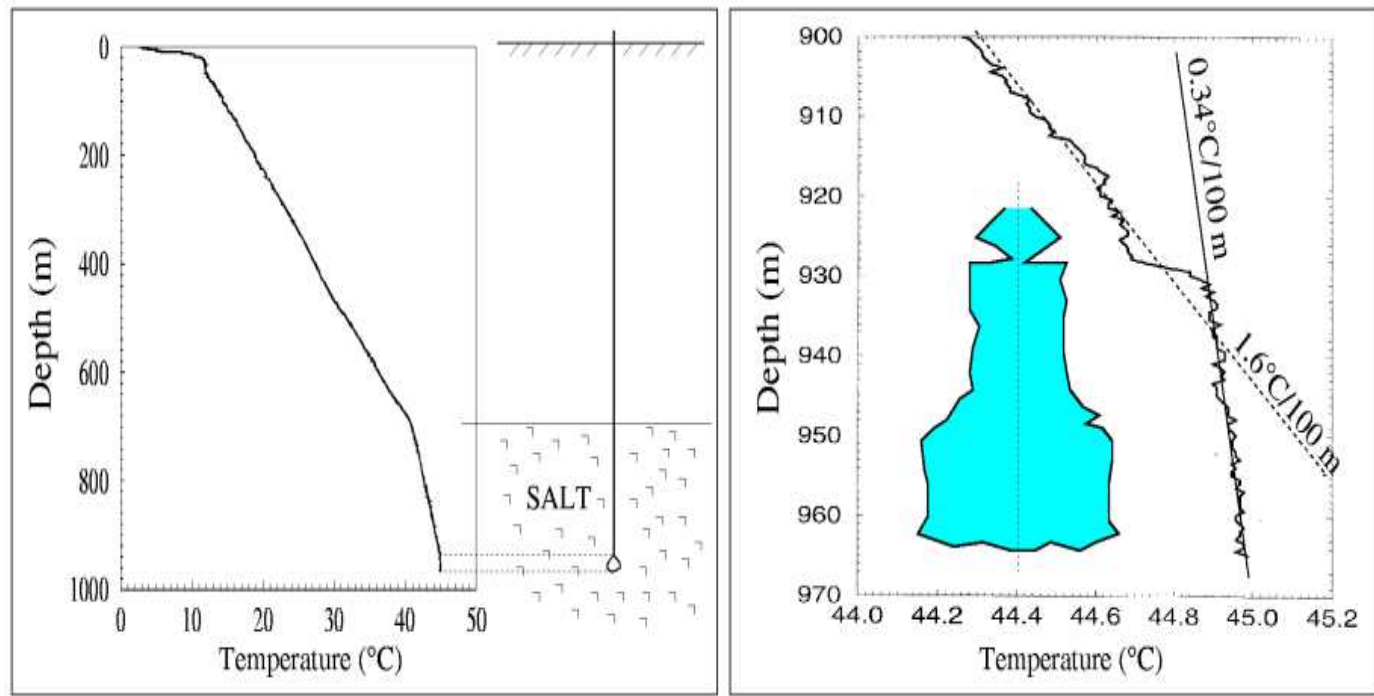

Figure 1. Temperature profile along the vertical axis of the EZ53 brine cavern from the Etrez site in France ( ${ }^{1}$ Brouard, 1998, courtesy of Storengy.
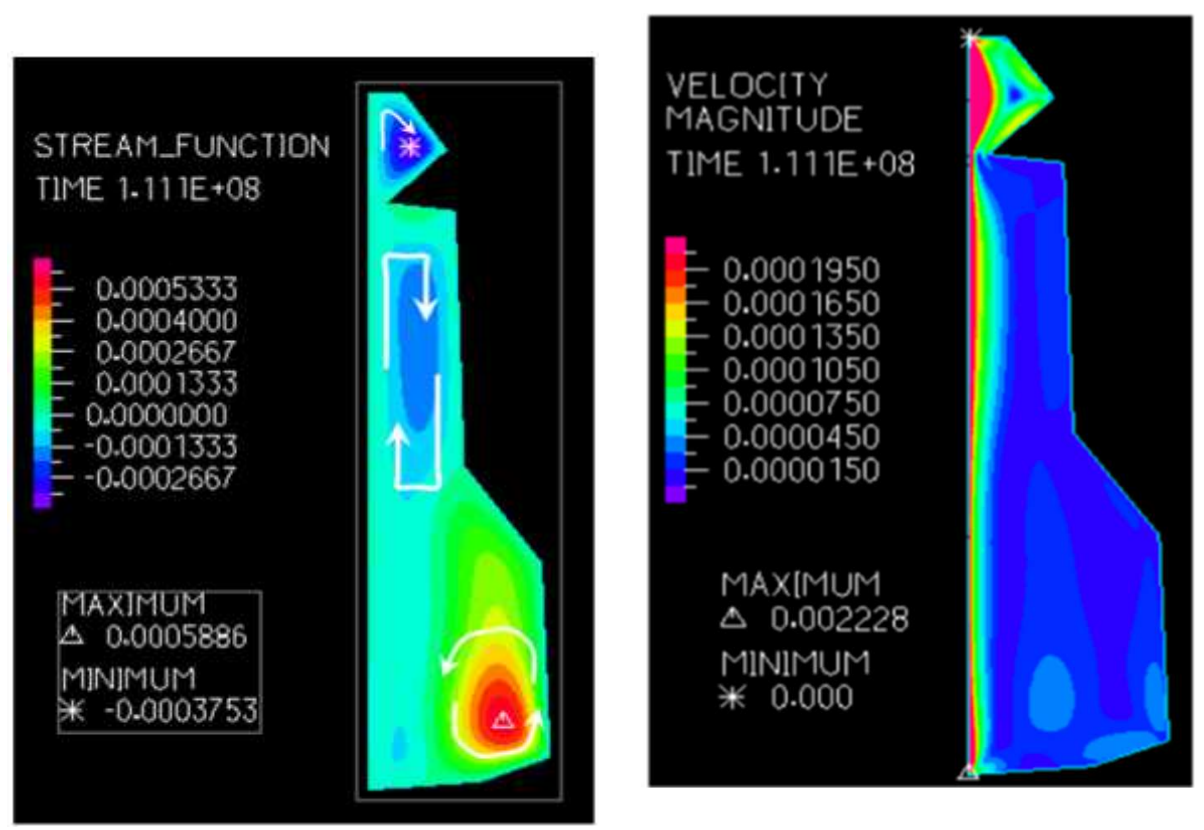

Figure 2. As-computed convection cells in the EZ53 cavern, assuming axisymmetry. Left: iso-values of the streamline function; right: velocity magnitude ( ${ }^{2}$ Karimi-Jafari, 2007). 


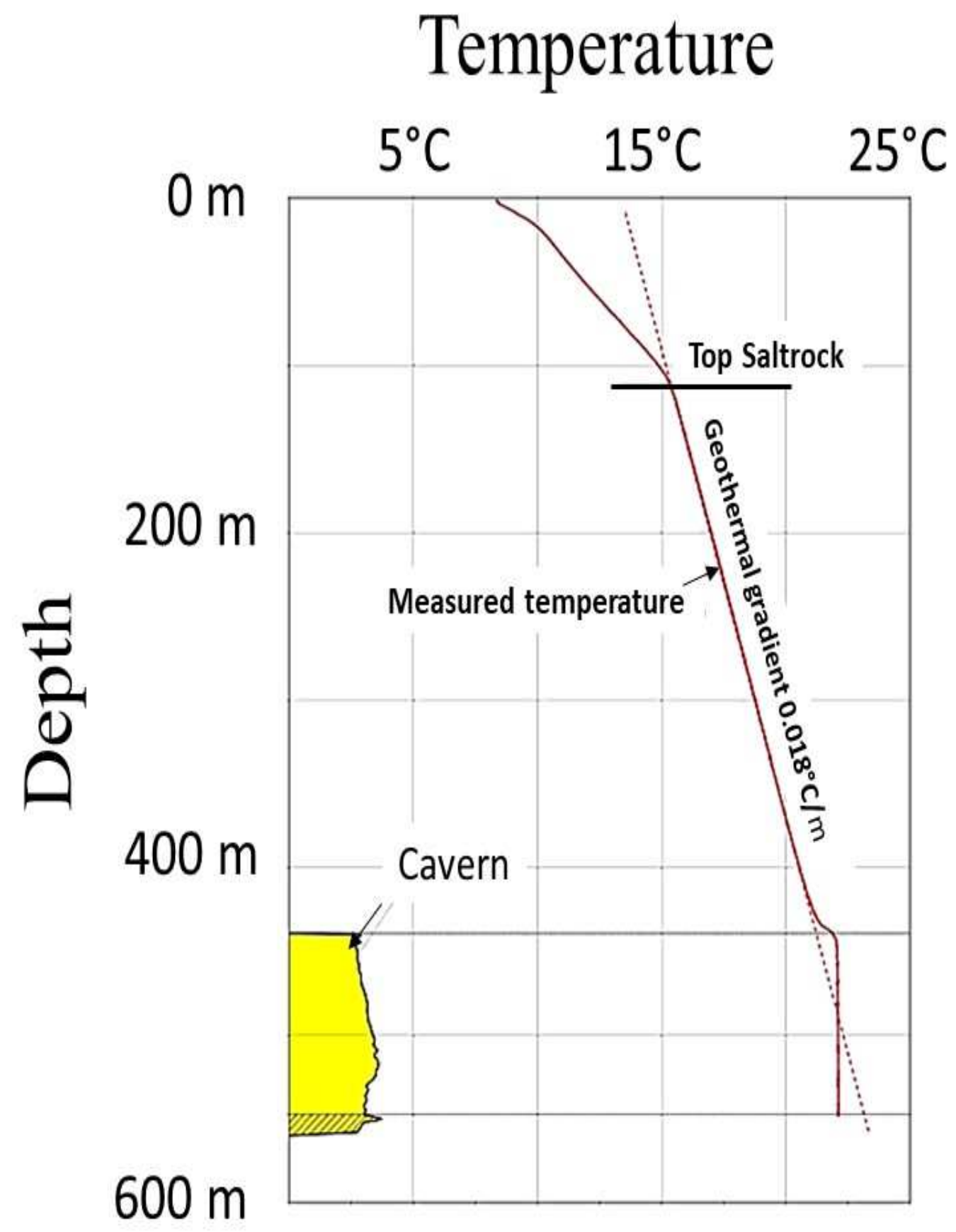

Figure 3. Temperature profile along the vertical axis of symmetry in a brine cavern (After ${ }^{3}$ Banach and Klafki, 2009). 

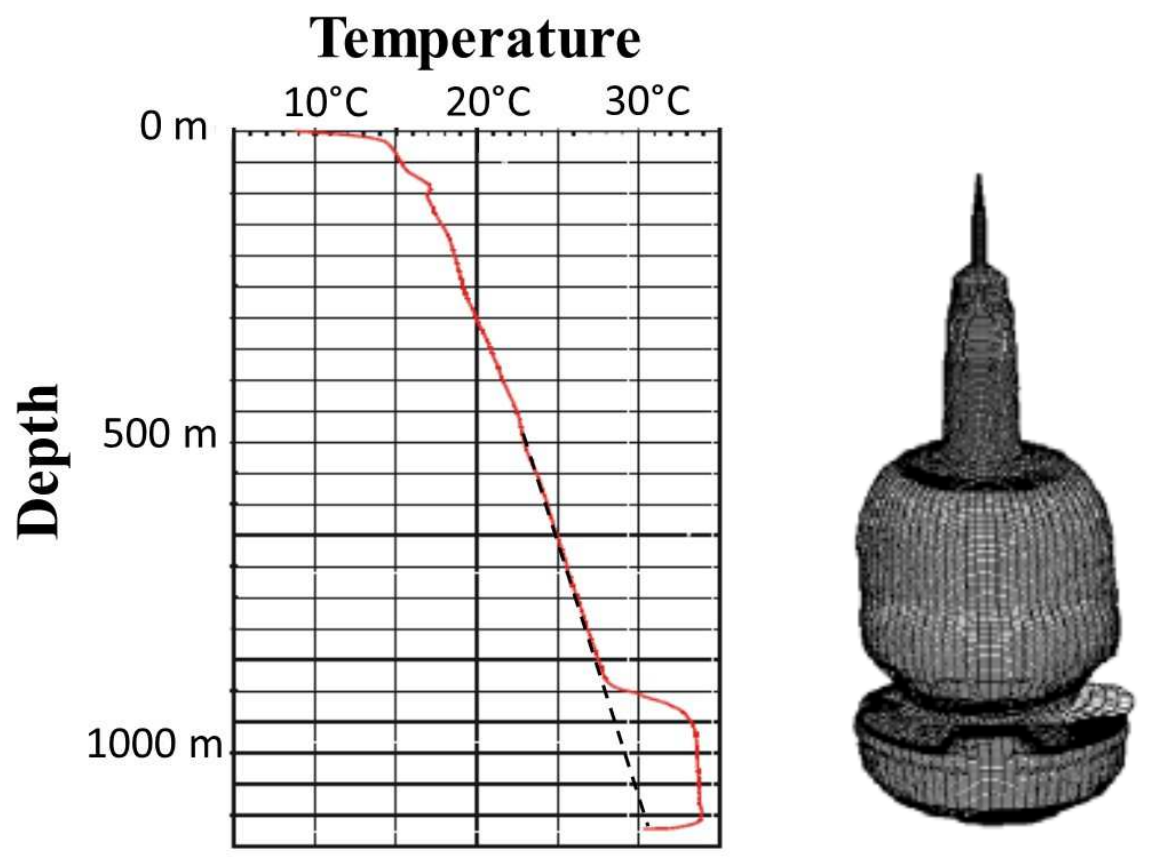

Fig. 4. Temperature profile in the S107 natural gas cavern, Stassfurt, Germany (left); cavern shape selected for numerical computations (right) (after ${ }^{4}$ Klafki et al., 2003).

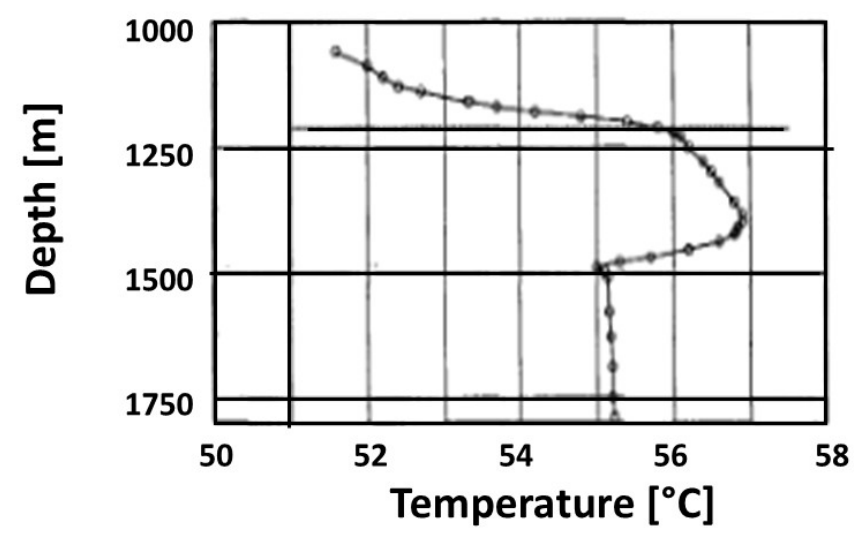

Figure 5. Temperature profile in a cavern at Etzel, Germany; roof depth is slightly more than $1200 \mathrm{~m}$, and the gas interface is slightly above $1500 \mathrm{~m}$ (After ${ }^{13}$ Thaule and Gentzsch, 1994). 


\section{Temperature $\left({ }^{\circ} \mathbf{C}\right)$}

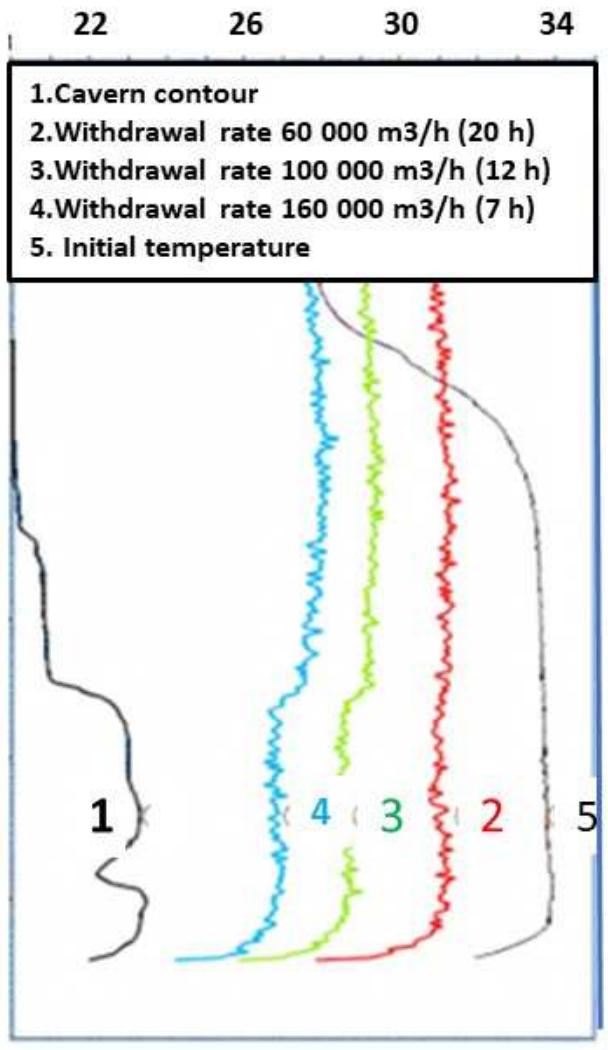

Withdrawal

\section{Temperature $\left({ }^{\circ} \mathrm{C}\right)$}

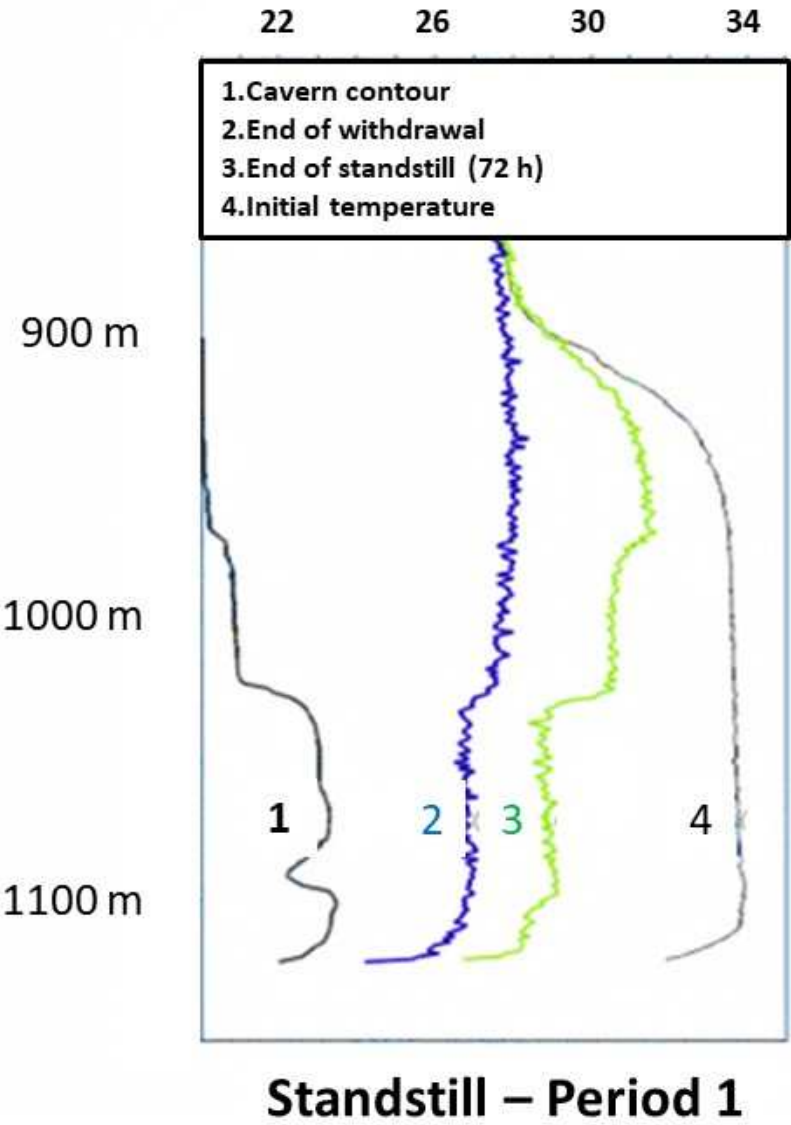

Figure 6. The cavern profile (1) is drawn on the left side of each picture. In the left illustration, temperature profiles before (5) and after $(2,3,4)$ three consecutive withdrawals are represented; the right illustration represents how temperature reaches thermal equilibrium after the withdrawals are completed $(2,3)$ (After ${ }^{4}$ Klafki et al., 2003). 


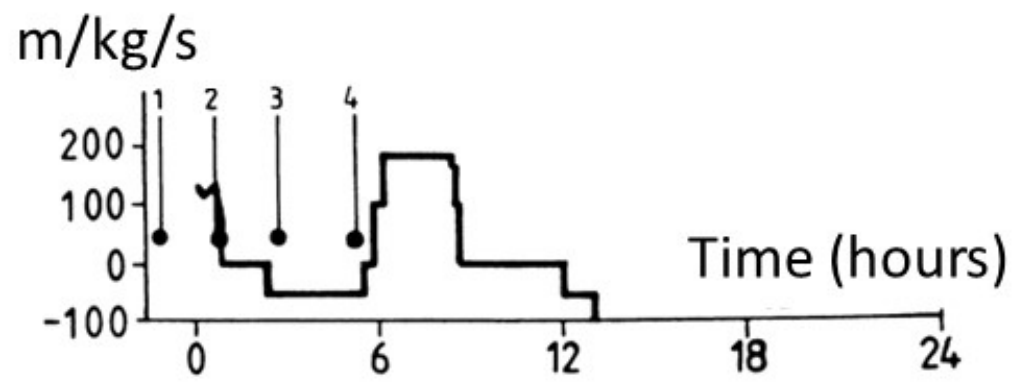

Depth $(\mathrm{m})$

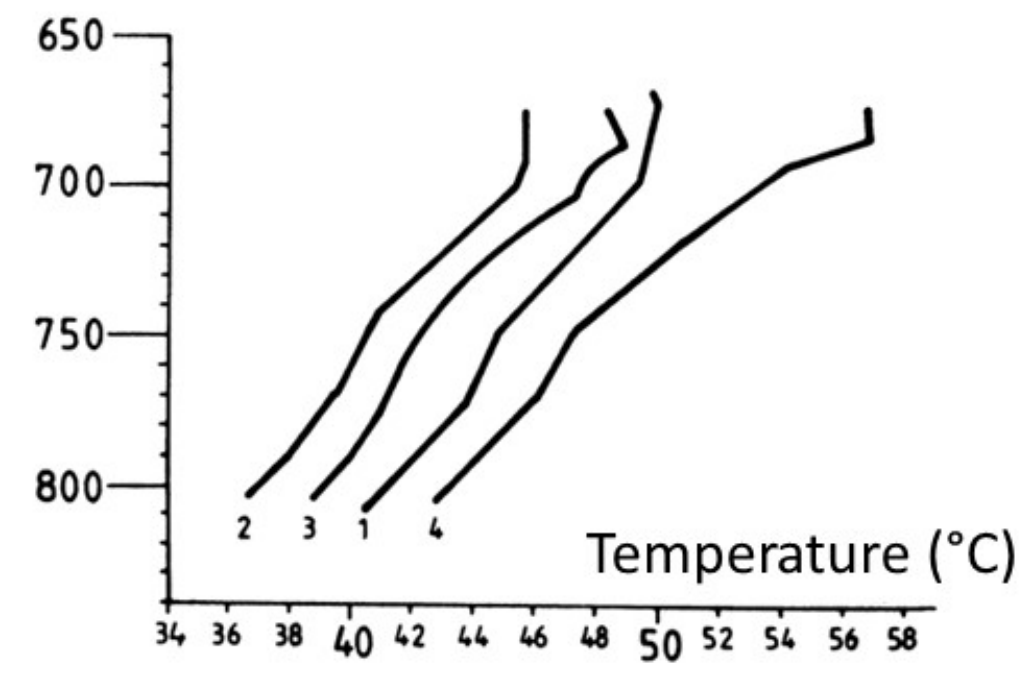

Figure 7. Gas flowrates (above); for air, $1 \mathrm{Nm}^{3}=1.29 \mathrm{~kg}$. Temperature profiles along a vertical axis in the NK1 cavern of the Huntorf CAES after injections and withdrawals (below) (After ${ }^{15}$ Quast, 1983).

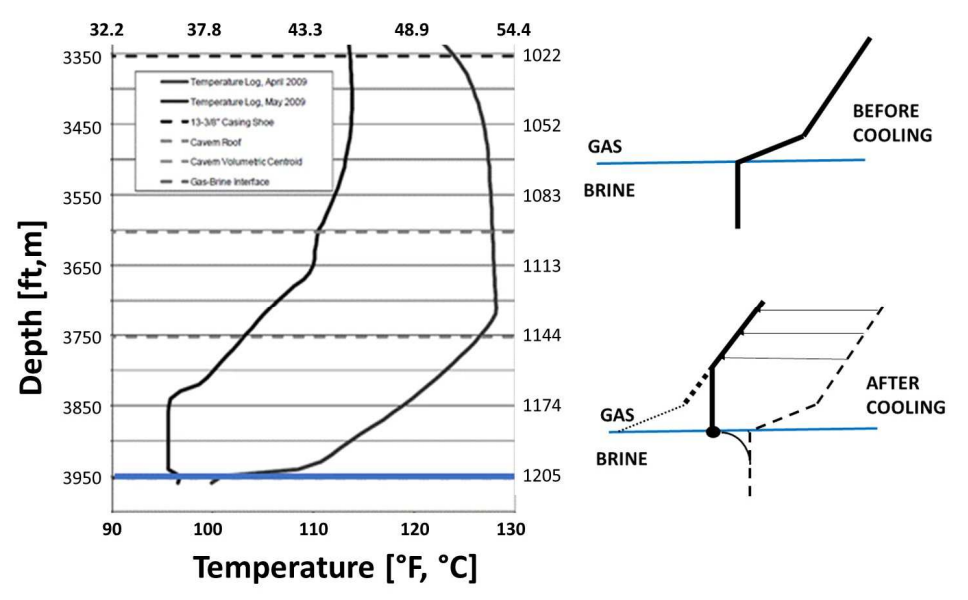

Figure 8. Enterprise Cavern 1 (left) - At a 3751-ft (1144-m) depth, gas pressure was decreased from $2728 \mathrm{psi}$ (18.8 MPa) to 1994 psi (13.7 MPa) between April 2009 and May 2009 (After ${ }^{16}$ Skaug et al., 2010); (right) a tentative explanation. 


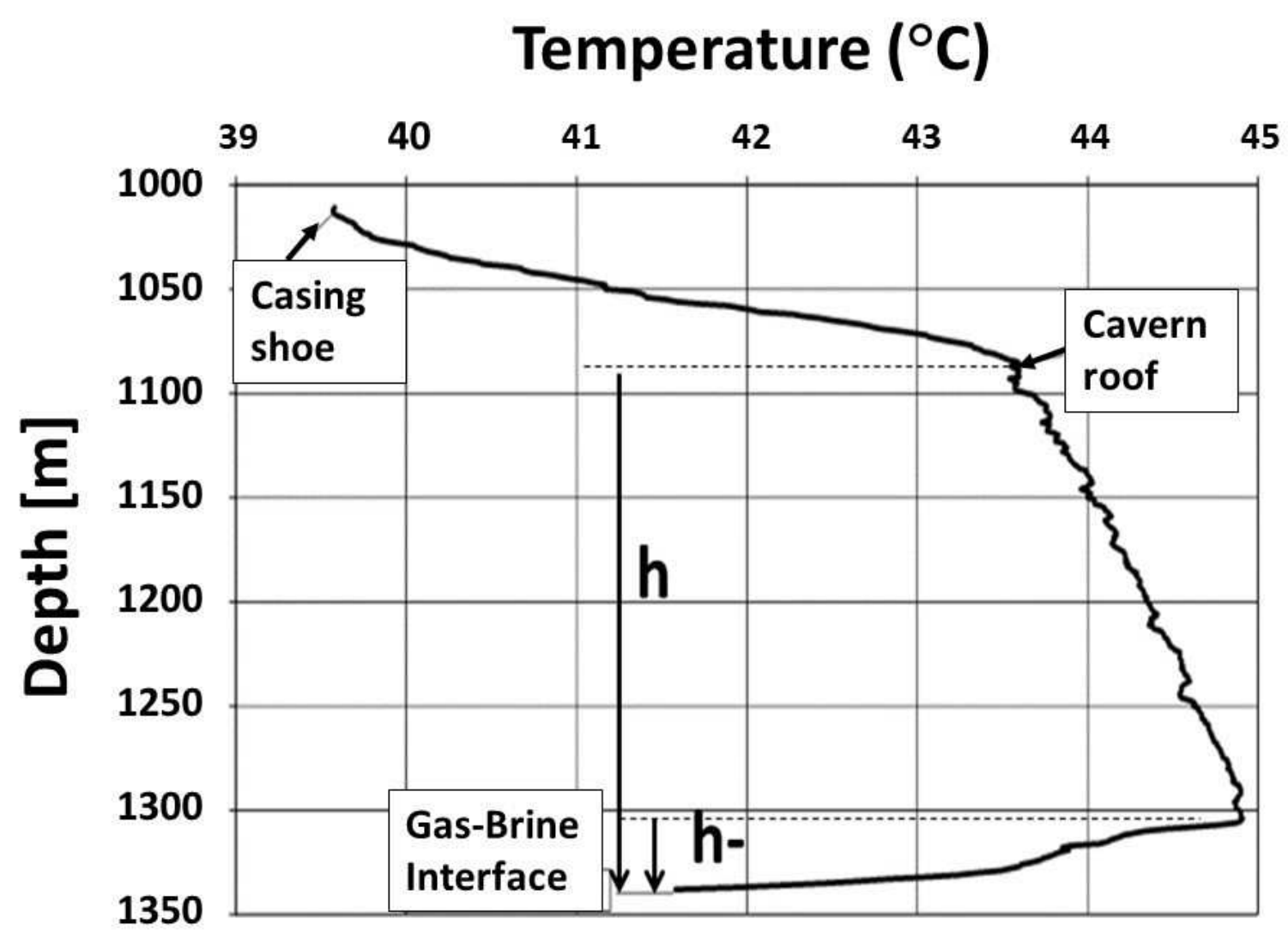

Figure 9. Temperature profile in an anonymous gas cavern: the temperature gradient in the upper part of the cavern is $G=6 \times 10^{-30} \mathrm{C} / \mathrm{m}$; it is negative above the sump. (After ${ }^{17}$ Berger et al., 2002). 


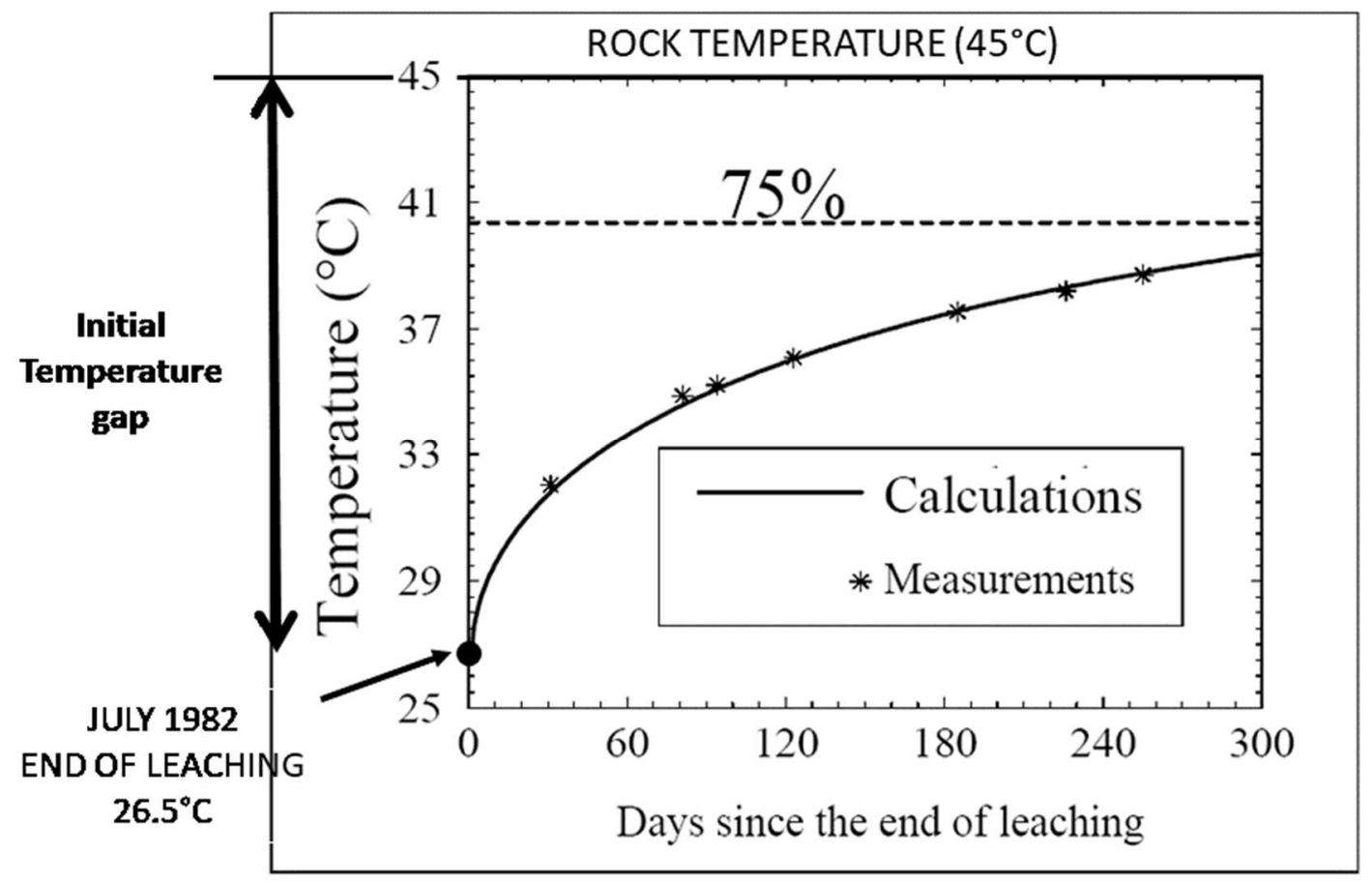

Figure 10. Temperature evolution in an $8000-\mathrm{m}^{3}$ cavern after solution mining is completed (Courtesy of Storengy). 

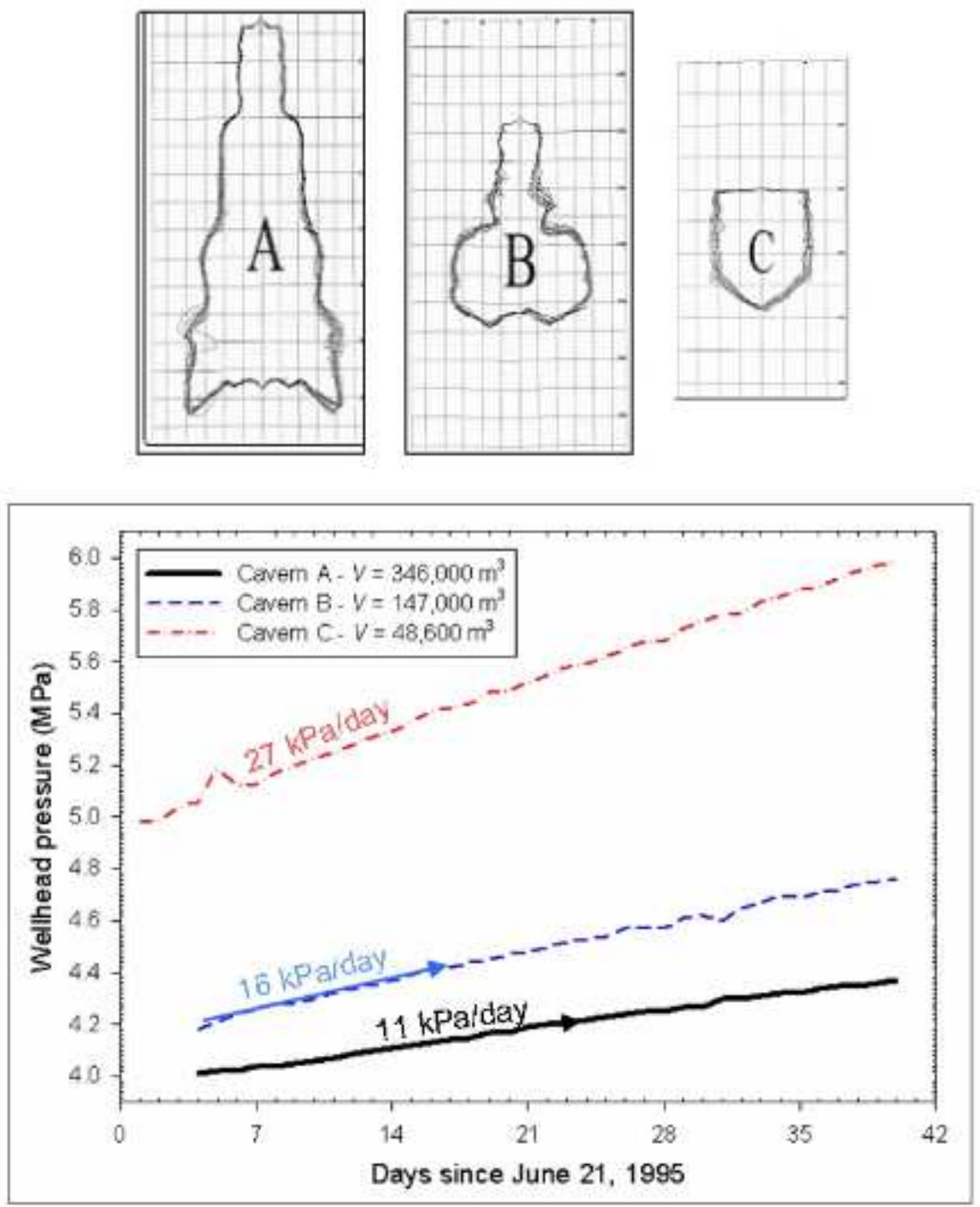

Figure 11. Pressure evolution in three caverns from the same site whose sizes are different ( ${ }^{30}$ Van Sambeek et al., 2005; courtesy of Storengy).
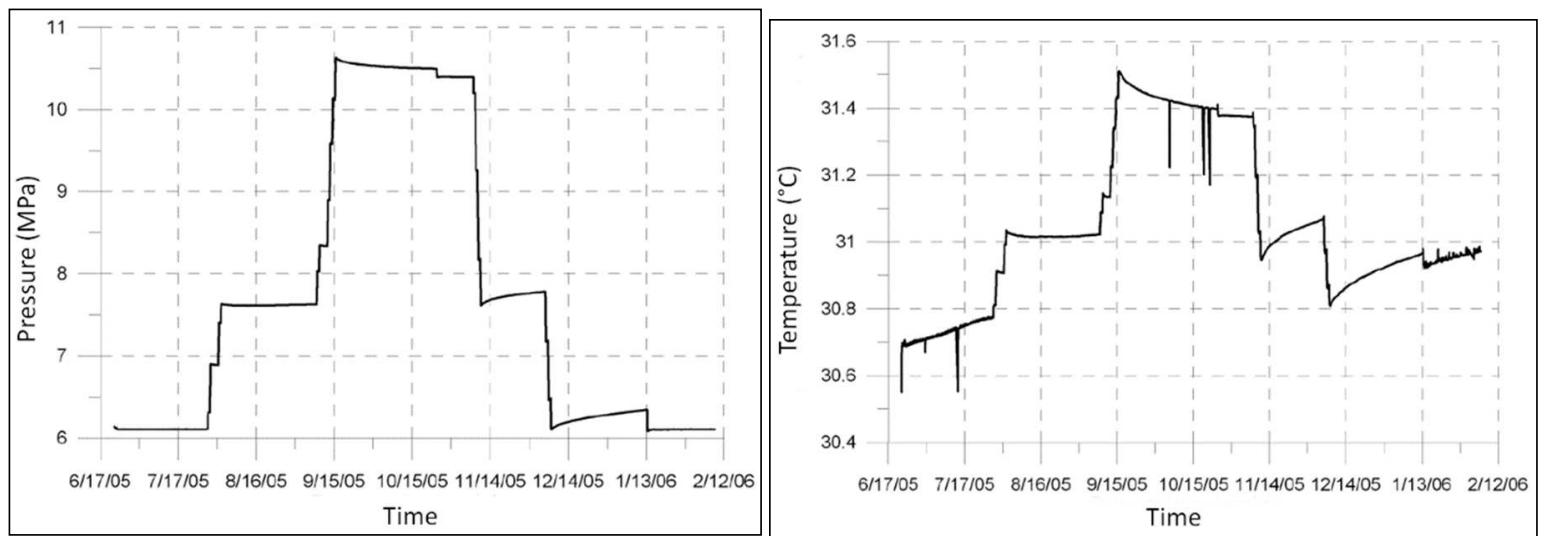

Figure 12. Pressure and Temperature evolutions in an oil cavern during injections/withdrawals ( ${ }^{34}$ Gatelier et al., 2008). 


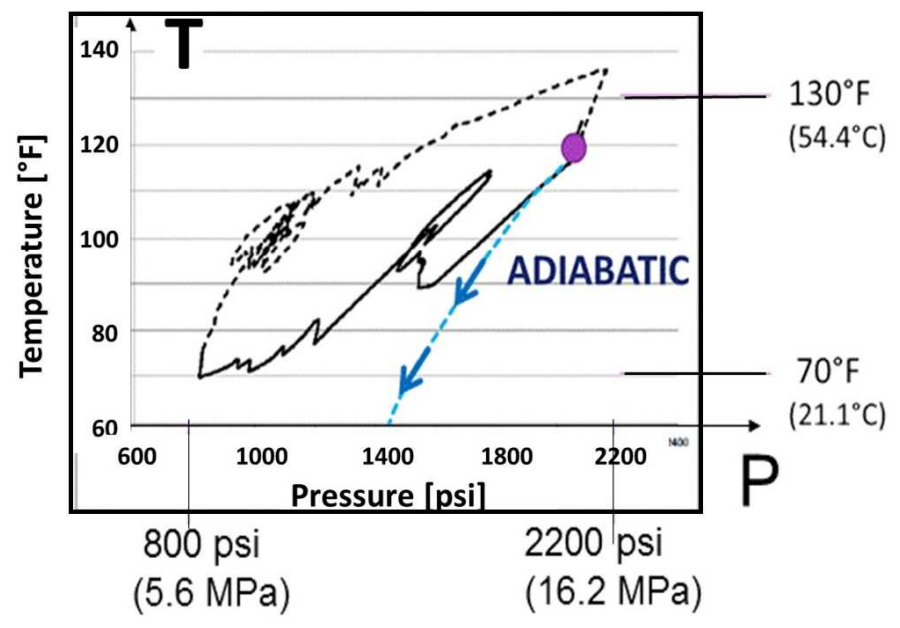

Figure 13. Cavern temperature as a function of cavern pressure during a cycle in a gas storage cavern in the Gulf of Mexico. The blue dotted line represents the computed adiabatic behavior $P^{a d} / P_{0}=\left(T^{a d} / T_{0}\right)^{1-1 / \gamma}\left(\right.$ afte $^{35}$ Heath and Benefield, 2010).

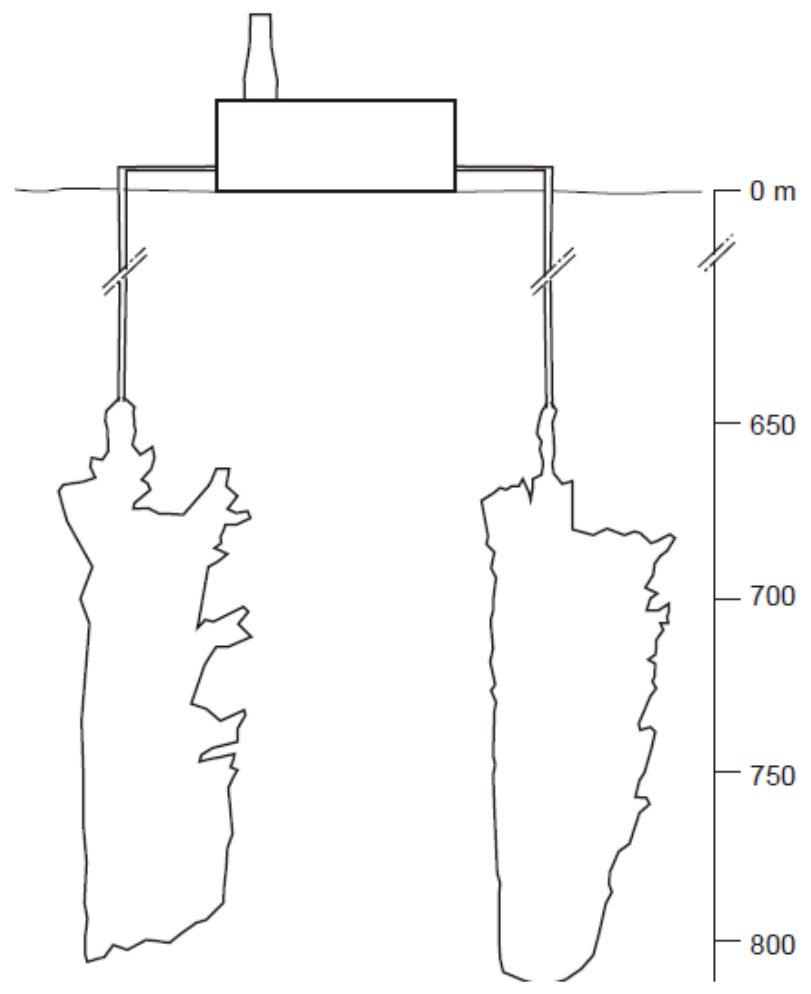


Figure 14. Vertical cross sections of Huntorf NK1 (left) and NK2 (right) caverns. From ${ }^{45}$ Crotogino et al. 2001.
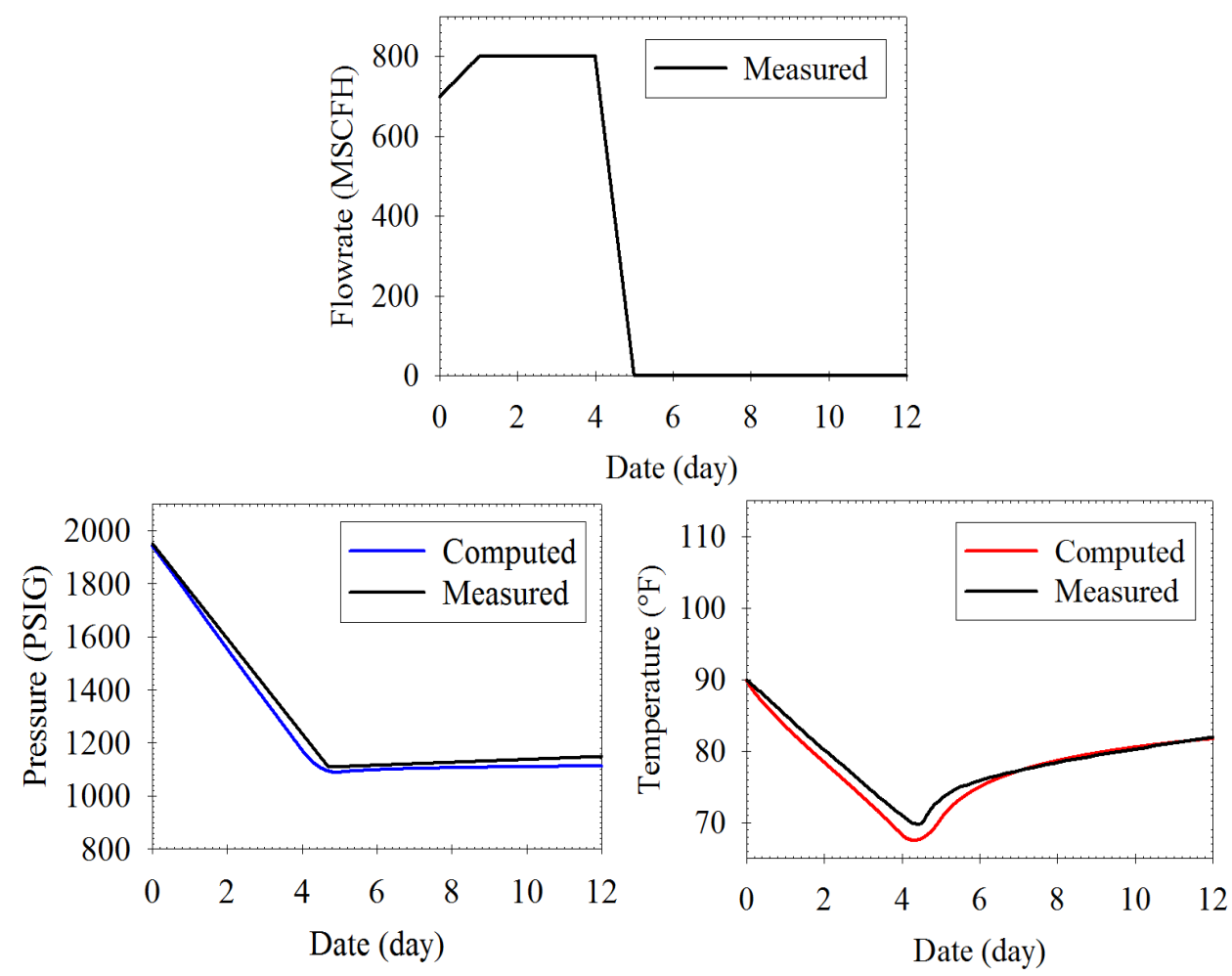

Figure 15. Melville Cavern: Gas withdrawal rate, pressure and temperature evolutions as observed (after ${ }^{46}$ Crossley, 1996) and as computed: 1 MSCFH $=28,317 \mathrm{Nm}^{3} / \mathrm{hr}$, $1 \mathrm{MPa}=145 \mathrm{psig}$ and $20^{\circ} \mathrm{C}=68^{\circ} \mathrm{F}$.

Table 2. Values of $K_{R} / \sqrt{\pi k_{R}}$

\begin{tabular}{|c|c|c|c|c|c|}
\hline & $\begin{array}{c}K_{\text {salt }} \\
\mathrm{W} / \mathrm{m}^{\circ}{ }^{\circ} \mathrm{C}\end{array}$ & $\begin{array}{c}\rho_{\text {salt }} \\
\mathrm{kg} / \mathrm{m}^{3}\end{array}$ & $\begin{array}{c}C_{\text {salt }} \\
\mathrm{J} / \mathrm{kg}^{\circ}{ }^{\circ} \mathrm{C}\end{array}$ & $\begin{array}{c}k_{\text {salt }} \\
\mathrm{m}^{2} / \mathrm{s}\end{array}$ & $\begin{array}{c}K_{\text {salt }} / \sqrt{\pi k_{\text {salt }}} \\
\mathrm{SI}\end{array}$ \\
\hline 1 & 5.2 & 2174 & 800 & $2.99 \times 10^{-6}$ & 1700 \\
\hline 2 & 5.5 & 2180 & 870 & $2.9 \times 10^{-6}$ & 1820 \\
\hline 3 & 5 & 2200 & 860 & $2.64 \times 10^{-6}$ & 1740 \\
\hline 4 & 6.1 & 2200 & 921 & $3.0 \times 10^{-6}$ & 1980 \\
\hline
\end{tabular}

(1 = ${ }^{40}$ Pellizzaro et al., $2011 ; 2={ }^{41}$ Staudtmeister et al., 2011 $3={ }^{42}$ Blanco Martin et al., 2015; $4={ }^{43}$ Brouard Consulting, 2019. 
Table 1. Gas thermal constants, from ${ }^{5}$ Gas Encyclopedia, Air Liquide. Constants are

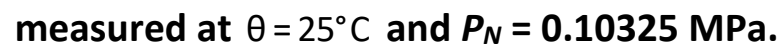

\begin{tabular}{|l|c|c|c|c|c|c|c|}
\hline Gas & $C_{p}(\mathrm{~J} / \mathrm{kg} / \mathrm{K})$ & $C_{v}(\mathrm{~J} / \mathrm{kg} / \mathrm{K})$ & $\gamma(-)$ & $\mu(\mathrm{Pa} . \mathrm{s})$ & $K_{F}(\mathrm{~W} / \mathrm{m} / \mathrm{K})$ & $\operatorname{Pr}=\mu C_{P} / K$ & $G_{a d}=g / C_{P}$ \\
\hline $\begin{array}{l}\text { Air } \\
\left(25^{\circ} \mathrm{C}\right)\end{array}$ & 1006 & 718 & 1.402 & $1.84 \times 10^{-5}$ & $26 \times 10^{-3}$ & 0.7 & $9.8 \times 10^{-3}$ \\
\hline $\begin{array}{l}\mathrm{CH}_{4} \\
\left(25^{\circ} \mathrm{C}\right)\end{array}$ & 2232 & 1708 & 1.306 & $1.1 \times 10^{-5}$ & $34 \times 10^{-3}$ & 0.72 & $4.4 \times 10^{-3}$ \\
\hline $\mathrm{H}_{2}$ & 14306 & 10180 & 1.405 & $0.89 \times 10^{-5}$ & $185 \times 10^{-3}$ & 0.69 & $0.7 \times 10^{-3}$ \\
\hline $\mathrm{O}_{2}$ & 920 & 658 & 1.397 & $2.06 \times 10^{-5}$ & $26 \times 10^{-3}$ & 0.73 & $10.6 \times 10^{-3}$ \\
\hline $\mathrm{CO}_{2}$ & 851 & 657 & 1.29 & $1.49 \times 10^{-5}$ & $16 \times 10^{-3}$ & 0.79 & $11.5 \times 10^{-3}$ \\
\hline
\end{tabular}

